MANCHESTER

1824

†⿺

Economics

Discussion Paper Series

EDP-1219

The interest rate - exchange rate nexus: exchange rate regimes and policy equilibria

Christoph Himmels

Tatiana Kirsanova

September 2012

Economics

School of Social Sciences

The University of Manchester

Manchester M13 9PL 


\title{
The interest rate - exchange rate nexus: exchange rate regimes and policy equilibria
}

\author{
Christoph Himmels* \\ Tatiana Kirsanova ${ }^{\dagger}$ \\ University of Exeter \\ University of Exeter
}

November 2, 2009

\begin{abstract}
We study a credible Markov-perfect monetary policy in an open New Keynesian economy with incomplete financial markets. We demonstrate the existence of two discretionary equilibria. Following a shock the economy can be stabilised either 'quickly' or 'slow', both dynamic paths satisfy conditions of optimality and time-consistency. The model can help us to understand sudden change of the interest rate and exchange rate volatility in 'tranquil' and 'volatile' regimes even under a fully credible 'soft peg' of the nominal exchange rate in developing countries.
\end{abstract}

Key Words: Small open economy, Incomplete financial markets, Discretionary Monetary policy, Multiple Equilibria

JEL References: E31, E52, E58, E61, C61,F4

${ }^{*}$ Address: Department of Economics, Business School, University of Exeter, Streatham Court, Rennes Drive, Exeter EX4 4PU; e-mail ch308@exeter.ac.uk.

${ }^{\dagger}$ Address: Department of Economics, Business School, University of Exeter, Streatham Court, Rennes Drive, Exeter EX4 4PU; e-mail t.kirsanova@exeter.ac.uk 


\section{Introduction}

Fixing nominal exchange rates is frequently justified as a way to avoid excessive variability of economic variables, in particular in developing countries. The idea behind an exchange rate peg is that it will anchor inflation expectations, increase trade directly through lower uncertainty and smaller adjustment costs, and indirectly through its effect on the allocation of resources and government policies (see Côte (1994)). It may also encourage investment into long-term projects due to lower exchange rate risk/ transaction costs and therefore has a positive economic impact (see Prasad et al. (2003)). Being prone to speculative attacks hard pegs became less popular, especially after the Asian crisis of 1997. However, recent evidence suggests that monetary authorities in many developing countries still see nominal exchange rate targeting as their priority, despite that they officially claim to have floating regimes. ${ }^{1}$ Developing and emerging countries like Indonesia, Malaysia, Thailand, South Korea, Turkey, Russia adopted de jure flexible exchange rate regimes, but de facto the exchange rate remained one of the most important if not the only target of their monetary policy. ${ }^{2}$ Reinhart and Rogoff (2004) report that a crawling peg was the most common type of exchange rate arrangement in the Asian emerging countries between 1990 and 2001.

Despite the post-1997 decade was relatively tranquil in developing and emerging countries ${ }^{3}$, the exchange rate volatility under these 'soft pegs' varied over time. There is a number of studies that document difficulties in explaining these sudden changes in 'regimes' with higher or lower volatilities. ${ }^{4}$ Theoretical explanations for these different regimes include non-rational behaviour, non-linear decisions, heterogeneity of agents like the presence of 'noise traders' and so on (see Jeanne and Rose (2002) for an important example).

The main aim of this paper is to present a much simpler model that can help to understand some of these empirical facts. We claim that the way how monetary policy is conducted can be responsible for the existence of time periods with large difference in the volatility of macroeconomic variables. We employ a simple linear stochastic model that has become the workhorse model in monetary economics and abstract from many features that may characterise many developing or emerging countries, e.g. capital control or incomplete exchange rate pass-through. However, we account for incomplete financial markets and study discretionary monetary policy. Both of these features are fairly common in developing countries: financial markets are incomplete and governments cannot precommit. The above set-up is sufficient to generate multiple policy equilibria that will exist even in more detailed models. Specifically, we show the existence of two rational expectations equilibria that are associated with different speeds of adjustment towards the steady state and therefore with different volatilities of all macroeconomic variables.

The key to multiplicity is time-consistency of discretionary policy and dynamic complemen-

\footnotetext{
${ }^{1}$ See e.g Levy-Yeyati and Sturzenegger (2005) and Calvo and Reinhart (2002).

${ }^{2}$ See Rahmatsyah et al. (2002) for Thailand, Dogolnar (2002) for Turkey, Korea, Malaysia, Indonesia and Pakistan, and Arize et al. (2000) for 13 developing countries.

${ }^{3}$ We do not take into account the recent financial crisis.

${ }^{4}$ See e.g. Engel and Hamilton (1990), Clarida et al. (2003) or Chen (2006) who apply Markov-switching models to explain these changes. These models have also been employed to describe exchange rate behaviour in floating regimes. However, their succes is still a matter of current debate see e.g. again Clarida et al. (2003) and Engel et al. (2007).
} 
tarities. ${ }^{5}$ Under time consistency, the policymaker takes current and future economic conditions into account, but can only commit to current behavior. Economic conditions are affected by the response of the rational private sector and any response is based on a forecast of future economic conditions. As a consequence multiple equilibria may arise: Future policies respond to a state that is at least partly determined by forecasts of that policy. Different sets of beliefs about the future policy generate different future courses for policy to follow. Therefore, if the economy is hidden by a shock, it can follow one of several adjustment paths. The volatility along these paths is different. In presence of the several equilibria, coordination failure happens: the agents can choose any of them. A sunspot decides which one will realise.

We demonstrate how the existence of strategic complementarities in our model generates multiplicity of equilibria. ${ }^{6}$ Under conventional inflation targeting, following an interest rate increase, the effect of consumption on the terms of trade reinforces the effect of the interest rate on the terms of trade. Thus we have a strategic complementarity between consumption and the terms of trade in their effect on marginal cost, which are crucial for the control of inflation. The resulting two equilibria can be classified as 'dry/patient' and 'wet/impatient', based on the observed strength of interest rate responses. Then we look at a policymaker who introduces an additional positive weight in its policy objective that punishes the volatility of the nominal exchange rate (provided that the anchor country ensures price stability). In this case the 'wet/impatient' equilibrium becomes non-existent, while another equilibrium with even lower social welfare arises. When the weight on the exchange rate target completely dominates other terms in the objective of the policymaker ('currency peg'), the policymaker is able to stabilise the exchange rate completely if there is a common belief in a stable nominal exchange rate. However, there is another equilibrium: if there is a common belief that the nominal exchange rate is going to depreciate/appreciate in the future - non-zero exchange rate volatility is consistent with targeting policy - it becomes optimal for a policymaker to validate these beliefs and generate the forecasted depreciation/appreciation. This is in line with empirical work by Engel et al. (2007) who find that short-run movements in exchange rates are primarily determined by changes in expectations. If there is a coordination failure then the economy may be trapped in the worst equilibrium with high volatility in all economic variables.

Our paper is also related to the work on 'optimal delegation'. For discretionary policy Rogoff (1985) shows that it may be desirable for a society to allow for difference between the objective function of the monetary authority and the social objective in order to improve overall social welfare. ${ }^{7}$ We demonstrate that adding the exchange rate stabilisation target to social targets can marginally improve social welfare but only in the worst equilibrium, the additional exchange target is damaging for the best equilibrium. We argue that in our framework the 'soft peg' is, generally speaking, undesirable.

The paper is organized as follows. The next section outlines the model. Section 3 discusses the two policy equilibria for two regimes, inflation targeting and nominal exchange rate targeting.

\footnotetext{
${ }^{5}$ See King and Wolman (2004) for a non-linear model and Blake and Kirsanova (2008) for a general discussion of multiplicity in LQ RE models under discretion.

${ }^{6}$ See Cooper and John (1988) and King and Wolman (2004) for a discussion about the relationship between mulitiplicity and complementarity.

${ }^{7}$ A non-exhaustive list includes Rogoff (1985) and Svensson (1997) on inflation conservatism, Woodford (2003b) on interest rate smoothing policy and Vestin (2006) on price-level targeting.
} 
Section 4 concludes.

\section{Model}

The framework is relatively standard and builds heavily on the small open economy model introduced by Galí and Monacelli (2005), but we allow for a non zero current-account balance by including incomplete financial markets following a framework proposed by Benigno (2001). ${ }^{8}$ There are two economies: the small open economy and the rest of the world. The economic performance and domestic policy decisions of the small open economy do not have any impact on the rest of the world. Both economies are populated by a continuum of infinity-living households, which consume two goods. One is produced domestically and the other good is imported from the rest of the world, which we treat as a single, large 'foreign country'. The law of one price holds, but deviations from purchasing power parity (PPP) arise due to the existence of home bias in consumption. Production takes place in two stages. First, there is a continuum of intermediate goods firms, which produce a differentiated input. In the second stage final goods producers combine these inputs into output and sell them to households in both countries. Monopolistic competition and sticky prices are introduced to get a meaningful role for policy.

\subsection{Households}

Both economies, home $(H)$ and foreign $(F)$, consist of a continuum of infinity-living households and share identical preferences and technology. We assume that every household seeks to maximize

$$
\mathcal{E}_{0} \sum_{t=0}^{\infty} \beta^{t}\left[(1-\chi) \frac{C_{t}^{1-\sigma}}{1-\sigma}+\chi G_{t}-\frac{N_{t}^{1+\varphi}}{1+\varphi}\right],
$$

where $C_{t}$ denotes private consumption and $N_{t}$ hours of labour, while $G_{t}$ is an index of public consumption. $\beta$ is the subjective discount rate and $\mathcal{E}_{0}$ is the actuarial expectation at time $t=0$. Furthermore $\chi \in[0,1]$ is the weight attached to public consumption and $1 / \varphi$ measures the Frischelasticity of labour supply. In more detail $C_{t}$ is a composite consumption index defined by

$$
C_{t} \equiv\left[(1-\alpha)^{\frac{1}{\eta}}\left(C_{H, t}\right)^{\frac{\eta-1}{\eta}}+\alpha^{\frac{1}{\eta}}\left(C_{F, t}\right)^{\frac{\eta-1}{\eta}}\right]^{\frac{\eta}{\eta-1}}
$$

Parameter $\eta>0$ denotes the elasticity of substitution between domestic and foreign produced goods from the viewpoint of the domestic consumer. $C_{H, t}$ and $C_{F, t}$ are the Dixit-Stiglitz indexes of consumption of domestic and foreign goods given by the CES functions

$$
C_{H, t}=\left(\int_{0}^{1} C_{H, t}(j)^{\frac{\epsilon-1}{\epsilon}} d j\right)^{\frac{\epsilon}{\epsilon-1}}, \quad C_{F, t}=\left(\int_{0}^{1} C_{F, t}(j)^{\frac{\epsilon-1}{\epsilon}} d j\right)^{\frac{\epsilon}{\epsilon-1}},
$$

\footnotetext{
${ }^{8}$ In a very similar model De Paoli $(2009 b)$ analyzes the welfare effects of incomplete financial markets under Ramsey (precommitment) policy.
} 
where $j \in[0,1]$ denotes the good variety and $\epsilon>1$ is the elasticity of substitution between varieties of goods produced within a given country. Parameter $\alpha \in[0,1]$ is the weight of imported goods in private home consumption and is inversely related to the degree of home bias in preferences. Another interpretation for $\alpha$ is as a natural index of openness.

The nominal intertemporal budget constraint at time $t$ for household $i$ belonging to country $H$ is given by

$$
\begin{aligned}
& \int_{0}^{1}\left[P_{H, t}(j) C_{H, t}^{i}(j)+P_{F, t}(j) C_{F, t}^{i}(j)\right] d j+\mathcal{E}_{t}\left\{\frac{D_{H, t+1}^{i}}{1+i_{t}}\right\}+\mathcal{E}_{t}\left\{\frac{E_{t} D_{F, t+1}^{i}}{\left(1+i_{t}^{*}\right) \phi\left(\frac{E_{t} D_{F, t+1}}{P_{t}}\right)}\right\} \\
& \leq D_{H, t}^{i}+E_{t} D_{F, t}^{i}+\left(1-\tau_{t}\right)\left(W_{t}^{i} N_{t}^{i}+\Pi_{t}^{i}\right)+P_{H, t} T_{t}^{i}
\end{aligned}
$$

where $P_{H, t}(j)$ is the price of domestic good $j$ and $P_{F, t}(j)$ denotes the price of variety $j$ imported from country $F$, where the latter is expressed in domestic currency. $W_{t}^{i}$ is the nominal wage and $T_{t}^{i}$ denotes lump-sum taxes/transfers. $\tau$ denotes a country specific tax on nominal income and $E_{t}$ is the nominal exchange rate, given as the price of one of unit foreign currency in terms of home currency. We assume that the households share the revenues of owning firms in equal proportion. Following Woodford (2003a) we consider a cashless economy. Therefore the only explicit role played by money is to serve as a unit of account.

We introduce incomplete financial markets by applying a framework proposed by Benigno (2001). ${ }^{9}$ Households of country $H$ can trade in two nominal one-period, risk-free bonds. One bond is denominated in home currency, the other in foreign currency; but home currency denominated bonds are only traded domestically. So only the foreign bond is traded internationally. Furthermore, households belonging to country $H$ have to pay an intermediation cost, if they want to trade in the foreign bond. ${ }^{10}$ Let $D_{H, t}$ and $D_{F, t}$ denote the holdings in the home and foreign bond of all households belonging to country $H$. Let a "*" denote foreign country variables. The gross nominal interest rates of the home and foreign bond are given by $1+i$ and $1+i^{*}$, respectively. As mentioned above households have to pay a price to trade in the international market. These costs are determined by the function $\phi(\cdot)$. Function $\phi(\cdot)$ depends on the real holdings of the foreign assets in the entire economy, and therefore is taken as given by the domestic households. If a household belongs to a country which is in a "borrowing position" $\left(D_{F, t+1}<0\right)$, it will be charged with a premium on the foreign interest rate and if the household belongs to a country which is in a 'lending position' $\left(D_{F, t+1}>0\right)$, it receives a rate of return lower than the foreign interest rate. Along with Benigno (2001) we need the following restrictions on $\phi(\cdot): \phi(0)=1$ and $\phi(\cdot)$ is 1 only if $D_{F, t}=0$. Furthermore $\phi(\cdot)$ has to be a differentiable, decreasing function in the neighborhood of zero.

The intermediation profits $K$ are defined analogous to Benigno (2001)

$$
K=\frac{D_{F, t+1}^{*}}{P_{t}^{*}\left(1+i_{t}^{*}\right)}\left[\frac{1}{\phi\left(\frac{E_{t} D_{F, t+1}^{*}}{P_{t}^{*}}\right)}-1\right]>0
$$

\footnotetext{
${ }^{9}$ See Benigno (2009) for a generalized asset trading framework, that follows Ghironi et al. (2007).

${ }^{10}$ We introduce this cost to ensure stationarity, see Schmitt-Grohe and Uribe (2003).
} 
and shared equally among foreign households. The foreign budget constraint is then given as

$$
P_{t}^{*} C_{t}^{*}+\frac{D_{F, t+1}^{*}}{\left(1+i_{t}^{*}\right)}=D_{F, t}^{*}+\left(1-\tau_{t}^{*}\right)\left(W_{t}^{*} N_{t}^{*}+\Pi_{t}^{*}\right)+P_{F, t} T_{t}^{*}+K .
$$

The demand for good $j$ produced in a given country can be written as

$$
C_{H, t}(j)=\left(\frac{P_{H, t}(j)}{P_{H, t}}\right)^{-\epsilon} C_{H, t}, \quad C_{F, t}(j)=\left(\frac{P_{F, t}(j)}{P_{F, t}}\right)^{-\epsilon} C_{F, t},
$$

for all $j \in[0,1]$, where $P_{H, t}=\left(\int_{0}^{1} P_{H, t}(j)^{1-\epsilon} d j\right)^{\frac{1}{1-\epsilon}}$ and $P_{F, t}=\left(\int_{0}^{1} P_{F, t}(j)^{1-\epsilon} d j\right)^{\frac{1}{1-\epsilon}}$ are the price indexes for domestic and imported goods, whereby the latter is expressed in domestic currency.

Finally, the optimal condition of expenditures between domestic and imported goods is given by

$$
C_{H, t}=(1-\alpha)\left(\frac{P_{H, t}}{P_{t}}\right)^{-\eta} C_{t}, \quad C_{F, t}=\alpha\left(\frac{P_{F, t}}{P_{t}}\right)^{-\eta} C_{t},
$$

where $P_{t}=\left[(1-\alpha) P_{H, t}^{1-\eta}+\alpha P_{F, t}^{1-\eta}\right]^{\frac{1}{1-\eta}} P_{t}$ is the consumer price index (CPI) in country $H$. Note that if the economy is closed, $\alpha=0$, the CPI equals domestic prices. Correspondingly we can write total consumption expenditures by domestic households as $P_{t} C_{t}=P_{H, t} C_{H, t}+P_{F, t} C_{F, t}$. The aggregated budget constraint can therefore be rewritten as

$$
P_{t} C_{t}+\mathcal{E}_{t}\left\{\frac{D_{t+1}}{1+i_{t}}\right\}+\mathcal{E}_{t}\left\{\frac{E_{t} D_{t+1}^{*}}{\left(1+i_{t}^{*}\right) \phi\left(\frac{E_{t} D_{t+1}^{*}}{P_{t}}\right)}\right\}=D_{t}+E_{t} D_{t}^{*}+\left(1-\tau_{t}\right)\left(W_{t} N_{t}+\Pi_{t}\right)+P_{H, t} T_{t} .
$$

Maximizing (1) with respect to (3) yields the following FOCs:

$$
\begin{aligned}
C_{t}^{-\sigma} & =\beta\left(1+i_{t}\right) \mathcal{E}_{t}\left(C_{t+1}^{-\sigma} \frac{P_{t}}{P_{t+1}}\right) \\
C_{t}^{-\sigma} & =\beta\left(1+i_{t}^{*}\right) \phi\left(\frac{E_{t} D_{t+1}^{*}}{P_{t}}\right) \mathcal{E}_{t}\left(C_{t+1}^{-\sigma} \frac{P_{t}}{P_{t+1}} \frac{E_{t+1}}{E_{t}}\right) \\
C_{t}^{\sigma} N_{t}^{\phi} & =(1-\chi) \frac{W_{t}}{P_{t}} \\
E_{t} D_{t+1}^{*} & =\left(1+i_{t}^{*}\right) \phi\left(\frac{\mathcal{E}_{t} D_{t+1}^{*}}{P_{t}}\right)\left(E_{t} D_{t}^{*}+P_{H, t}\left(Y_{t}-G_{H, t}\right)-P_{t} C_{t}\right)
\end{aligned}
$$

Equation (4) is the standard Euler equation and determines the consumption smoothing behaviour of the households. Equation (5) is the Euler equation derived from the optimal choice of the foreign bond. Equation (6) is the standard labour supply condition. It determines the quantity of labor supplied as a function of real wage, given the marginal utility of consumption. Finally, equation (7) is the aggregate budget constraint, which is obtained by aggregating the 
budget constraints of the households together with the government budget constraint (defined below). To derive this equation we also assume that output is distributed over wage and profits $W_{t} N_{t}+\Pi_{t}=P_{H, t} Y_{t}$.

A similar Euler equation holds for country $F:{ }^{11}$

$$
\beta\left(\frac{C_{t}^{*}}{C_{t+1}^{*}}\right)^{-\sigma}\left(\frac{P_{t}^{*}}{P_{t+1}^{*}}\right)=\frac{1}{1+i_{t}^{*}} .
$$

In contrast to the complete market case the monotonic relationship linking consumption with world consumption and ToT/ real exchange rate (see e.g. Galí and Monacelli (2005)) breaks down. The incomplete financial market framework generates deviations from the uncovered interest parity (UIP). Combining (4) and (5) yields the optimal portfolio choice of the households of country $H$

$$
\left(1+i_{t}\right)=\left(1+i_{t}^{*}\right) \phi\left(d_{t}\right)\left(\frac{E_{t+1}}{E_{t}}\right),
$$

where we simplified $d_{t}=\frac{E_{t} D_{F, t+1}}{P_{t}} . \phi\left(d_{t}\right)$ can also be interpreted as a risk premium term on the exchange rate. ${ }^{12}$ If the economy is a net debtor, the domestic interest rate is above the foreign interest rate and if the economy is a net creditor the domestic interest rate is below the foreign interest rate. Therefore movements in the net foreign asset positions affect the interest differential between the two countries.

Combining (5) with the Euler equation of the foreign country (8) yields the international risk sharing condition

$$
\mathcal{E}_{t}\left[\left(\frac{C_{t+1}}{C_{t}}\right)^{-\sigma} \frac{P_{t}}{P_{t+1}}\right] \phi\left(d_{t}\right)=\mathcal{E}_{t}\left[\left(\frac{C_{t+1}^{*}}{C_{t}^{*}}\right)^{-\sigma} \frac{P_{t}^{*}}{P_{t+1}^{*}} \frac{E_{t}}{E_{t+1}}\right] .
$$

Note that if $d_{t} \equiv 0$ then $\phi\left(d_{t}\right)=1$ and the above equation simplifies to the standard international risk sharing relationship which is obtained in a complete securities markets setting (see e.g. Galí and Monacelli (2005)).

\subsection{Price and Exchange Rate Identities}

The terms of trade are defined as the price of foreign goods relative to the price of goods produced in country $H$ and given by

$$
S_{t} \equiv \frac{P_{F, t}}{P_{H, t}}
$$

Note that in this framework the PPP does not hold in the short run, because of the presence of home bias in consumption. However, PPP holds in a symmetric steady state $P_{H}=P_{F}$. Following Galí and Monacelli (2005) the foreign price index $P_{t}^{*}$ equals the foreign price of imported goods $P_{F, t}$. This results from the definition of the rest of the world as closed economy, implying that

\footnotetext{
${ }^{11}$ Because of Walras Law the foreign budget constraint is redundant (see Benigno (2001)).

${ }^{12}$ For empirical evidence and possible explanations of such a risk premium see e.g. Bergin (2006).
} 
country $H$ goods production is a negligible fraction of the world's consumption basket. Hence it follows $\pi_{t}^{*}=\pi_{F, t}$ for all $t$, where $\pi_{t}=\frac{P_{t}}{P_{t-1}}$.

Under the assumption of free-trade in all goods the law of one price holds for all individual goods at all times and implies

$$
P_{F, t}(j)=E_{t} P_{F, t}^{*}(j),
$$

for all $j \in[0,1] . \quad E_{t}$ is the nominal exchange rate and $P_{F, T}^{*}(j)$ is the price of a foreign good expressed in foreign currency. Aggregating across all goods implies

$$
P_{F, t}=E_{t} P_{F, t}^{*}
$$

The real exchange rate - the ratio of CPI inflations, expressed in domestic currency - is defined as

$$
\mathcal{Q}_{t}=\frac{E_{t} P_{t}^{*}}{P_{t}}
$$

\subsection{Government}

The government only provides goods and services which are produced in the domestic country. The public good aggregate of country $H$ is given by the CES function

$$
G_{H, t}=\left(\int_{0}^{1} G_{H, t}^{\frac{\epsilon-1}{\epsilon}}(j) d j\right)^{\frac{\epsilon}{\epsilon-1}}, \epsilon>1
$$

where $G_{H, t}(j)$ is the quantity of domestic good $j$ purchased by the government. The demand schedule of government spending is analogous to the consumption case

$$
G_{H, t}(j)=\left(\frac{P_{H, t}(j)}{P_{t}}\right)^{-\epsilon} G_{H, t} .
$$

Finally the government budget constraint in the home economy is given by

$$
\mathcal{E}_{t}\left\{\frac{D_{t+1}}{1+i_{t}}\right\}=D_{t}+P_{H, t}\left(G_{t}+T_{t}\right)-\tau P_{H, t} Y_{t}
$$

where $\tau$ is a tax on the nominal income of the domestic households and $G_{H, t}$ is government spending, whereby both are exogenous and financed by lump-sum taxes/ transfers $T_{t}$.

\section{$2.4 \quad$ Firms}

\subsubsection{Technology}

There is a continuum of monopolistic competitive firms $j \in[0,1]$ in both countries and each firm produces a differentiated good with a linear technology, represented by the production function

$$
Y_{t}(j)=A_{t} N_{t}(j)
$$


where $A_{t}$ is a exogenous, country-specific technology shock. The demand curve for each firm is given by

$$
Y_{H, t}(j)=\left(\frac{P_{H, t}(j)}{P_{H, t}}\right)^{-\epsilon} Y_{H, t}
$$

where $Y_{H, t}=\left(\int_{0}^{1} Y_{H, t}^{\frac{\epsilon}{\epsilon-1}}(j) d j\right)^{\frac{\epsilon-1}{\epsilon}}$ is the aggregate output index of country $\mathrm{H}$.

The amount of labour hired is given by

$$
N_{t} \equiv \int_{0}^{1} N_{t}(j) d j=\frac{Y_{t} Z_{t}}{A_{t}}
$$

where $Z_{t} \equiv \int_{0}^{1} \frac{Y_{t}(j)}{Y_{t}} d j$.

\subsubsection{Price setting}

The prices are set by monopolistic competitive firms facing price stickiness in a framework proposed by Calvo (1983). Calvo assumes that each period, there is a constant probability $1-\theta$ for a firm to adjust its price. This probability does not depend on the history of past price changes, but only on the random signal $\theta$. The expected time between price adjustments is $1 /(1-\theta)$. If the law of large numbers holds this implies that the fraction of firms not setting prices in period $t$ is $\theta$. The parameter $\theta$ measures the degree of nominal rigidity and a larger $\theta$ implies a higher degree of price stickiness. Firms not changing the price adjust their output to meet demand. Since the problem is symmetric, every firm faces the same decision problem and will choose the same optimal price $\bar{P}_{H, t}$, if it is allowed to reset in period $t$.

The $j^{t h}$ - intermediate firm maximizes the expected discounted sum of current and future profits

$$
\max _{\bar{P}_{H, t}(j)} \sum_{s=0}^{\infty} \theta^{s} Q_{t, t+s}\left[\frac{\bar{P}_{H, t}(j)}{P_{H, t+s}} Y(j)_{H, t+s}-\frac{W_{H, t+s}}{P_{t+s}} \frac{Y(j)_{H, t+s}(1-\chi)}{A_{H, t+s}}\right],
$$

subject to

$$
Y_{H, t+s}(j)=\left(\frac{\bar{P}_{H, t}(j)}{P_{H, t+s}}\right)^{-\epsilon} Y_{H, t+s}
$$

where $\bar{P}_{H, t}(j)$ is the price set by firm $j$ adjusting its price in the current period and $Q_{t, t+s}=$ $\beta^{s}\left(C_{t} / C_{t+s}\right)^{\sigma}\left(P_{t} / P_{t+s}\right)$ is the subjective discount factor of the households. The FOC gives the optimal price set in period $t$ and can be written as ${ }^{13}$

$$
\bar{P}_{H, t}=\frac{\sum_{s=0}^{\infty}(\theta)^{s} Q_{t, t+s}\left[\epsilon \frac{W_{H, t+s}}{P_{t+s}} P_{H, t+s}^{\epsilon} \frac{Y_{H, t+s}}{A_{H, t+s}}\right]}{\sum_{s=0}^{\infty}(\theta)^{s} Q_{t, t+s}\left[(\epsilon-1)\left(1-\tau_{H, t+s}^{s}\right) P_{t+s}^{-1} P_{H, t+s}^{\epsilon} Y_{H, t+s}(1-\chi)\right]} .
$$

\footnotetext{
${ }^{13}$ For the derivation of the FOC and the NKPC see e.g. Galí and Monacelli (2005).
} 
Finally, under this price setting structure the domestic price index involves according to

$$
P_{H, t} \equiv\left[\theta P_{H, t-1}^{1-\epsilon}+(1-\theta) \bar{P}_{H, t}^{1-\epsilon}\right]^{\frac{1}{1-\epsilon}} .
$$

Note that the price dynamics are a function of its last period value and the expected future path; other past prices are not needed. The exclusion of other past prices is a result of the assumption of specific factor markets. ${ }^{14}$.

\subsection{Equilibrium}

\subsubsection{Market clearing conditions}

The output of the small open economy can either be consumed domestically by the households or the government or can be exported. Assume that $C_{H, t}^{*}(j)$ is the world demand for domestic good $j$. Hence market clearing for good $j$ requires

$$
\begin{aligned}
Y_{H, t}(j) & =C_{H, t}(j)+C_{H, t}^{*}(j)+G_{H, t}(j) \\
& =\left(\frac{P_{H, t}(j)}{P_{H, t}}\right)^{-\epsilon}\left\{\left(\frac{P_{H, t}}{P_{t}}\right)^{-\eta}\left[(1-\alpha) C_{t}+\alpha^{*}\left(\frac{1}{\mathcal{Q}_{t}}\right)^{-\eta} C_{t}^{*}\right]+G_{H, t}\right\} .
\end{aligned}
$$

Plugging the pervious equation into the definition of aggregate domestic output $Y_{H, t}=$ $\left[\int_{0}^{1} Y_{t}(j)^{\frac{\epsilon-1}{\epsilon}} d j\right]^{\frac{\epsilon}{\epsilon-1}}$ yields

$$
Y_{H, t}=\left(\frac{P_{H, t}}{P_{t}}\right)^{-\eta}\left[(1-\alpha) C_{t}+\alpha^{*}\left(\frac{1}{\mathcal{Q}_{t}}\right)^{-\eta} C_{t}^{*}\right]+G_{H, t} .
$$

\subsubsection{Rest of the World}

In this section we derive the dynamic system that describes the evolution of the economic variables in the world economy. Essentially we impose a dynamic structure on the system of shocks that affect the small open economy.

Let $\hat{X}_{t}=\log X_{t}-\log X$ denote the log-deviation of variable $X_{t}$ from its steady state value $X$. We also denote $\hat{X}_{t}^{n} \log$-deviations of variables from their steady state values in the flexible price equilibrium. The final log-linearised system of first order conditions for the Rest of the World consists of the Euler equation (9) and Phillips curve (10):

$$
\begin{aligned}
\hat{C}_{t}^{*} & =\mathcal{E}_{t} \hat{C}_{t+1}^{*}-\frac{1}{\sigma}\left(\hat{\imath}_{t}^{*}-\mathcal{E}_{t} \hat{\pi}_{t+1}^{*}\right), \\
\hat{\pi}_{t}^{*} & =\beta \mathcal{E}_{t} \hat{\pi}_{t+1}^{*}+\frac{(1-\theta)(1-\theta \beta)}{\theta}\left((\sigma+\phi) \hat{C}_{t}^{*}-(\phi+1) \hat{A}_{t}^{*}\right)+\eta_{t}^{*} .
\end{aligned}
$$

and in the flexible price equilibrium without mark up shocks $\hat{C}_{t}^{* n}=\frac{(\phi+1)}{(\sigma+\phi)} \hat{A}_{t}^{*}$.

\footnotetext{
${ }^{14}$ See Woodford (2003a).
} 
We assume that the policymaker in the rest of the world solves a conventional inflation targeting problem. In a closed economy the social policy objective can be written as ${ }^{15}$

$$
\sum_{t=0}^{\infty} \beta^{t}\left(\hat{\pi}_{t}^{* 2}+\omega\left(\hat{C}_{t}^{*}-\hat{C}_{t}^{* n}\right)^{2}\right) .
$$

We assume that the policymaker acts under commitment. Such a policy choice ensures price level stability in the rest of the world. Since an exchange rate peg is often used to 'import' foreign inflation, the above choice of a price-stable foreign economy is important to ensure stability of the small open economy.

It is straightforward to demonstrate that the evolution of the rest of the world under control can be described by the following system

$$
\begin{aligned}
\zeta_{1 t} & =z_{10} \eta_{t}^{*}+z_{11} \zeta_{1 t-1}+z_{12} \zeta_{2 t-1}, \\
\zeta_{2 t} & =z_{20} \eta_{t}^{*}+z_{21} \zeta_{1 t-1}+z_{22} \zeta_{2 t-1}, \\
\hat{\pi}_{t}^{*} & =n_{\pi 0} \eta_{t}^{*}+n_{\pi 1} \zeta_{1 t-1}+n_{\pi 2} \zeta_{2 t-1}, \\
\hat{C}_{t}^{*} & =n_{c 0} \eta_{t}^{*}+n_{c 1} \zeta_{1 t-1}+n_{c 2} \zeta_{2 t-1}+\frac{(\phi+1)}{(\sigma+\phi)} \hat{A}_{t}^{*}, \\
\hat{\imath}_{t}^{*} & =f_{0} \eta_{t}^{*}+f_{1} \zeta_{1 t-1}+f_{2} \zeta_{2 t-1}-\frac{\sigma\left(1-\rho_{a^{*}}\right)(\phi+1)}{(\sigma+\phi)} \hat{A}_{t}^{*},
\end{aligned}
$$

where $\zeta_{1 t}$ and $\zeta_{2 t}$ are two Lagrange multipliers (that are set to zero in the initial moment) and all coefficients $z, n$ and $f$ are found numerically (see Söderlind (1999) among many others on solution algorithms). System (11)-(15) determines stochastic processes $\left\{\hat{\imath}_{t}^{*}, \hat{C}_{t}^{*}, \hat{\pi}_{t}^{*}\right\}$ as functions of shocks $\left\{\hat{A}_{t}^{*}, \eta_{t}^{*}\right\}$ that are assumed to be autoregressive processes:

$$
\begin{aligned}
& \eta_{t+1}^{*}=\rho_{\eta^{*}} \eta_{t}^{*}+\varepsilon_{\eta, t+1}, \\
& \hat{A}_{t+1}^{*}=\rho_{a^{*}} \hat{A}_{t}^{*}+\varepsilon_{a, t+1} .
\end{aligned}
$$

The small open economy is essentially affected by a system of shocks with a complex autoregressive structure, described by system (11)-(15).

\subsubsection{Small Open Economy}

In line with Benigno (2001) and De Paoli (2009b) we assume a symmetric steady state, which implies that the net foreign asset position is zero in the steady state. ${ }^{16}$ The final log-linearised

\footnotetext{
${ }^{15}$ See Woodford (2003). Here $\omega=\frac{(1-\theta)(1-\theta}{\theta \varepsilon}$.

${ }^{16}$ Although non-zero steady state holdings of foreign assets seems to be the empirical case (see e.g.Lane and Milesi-Ferretti (2002)) the simplification does not alter our results.
} 
system of first order conditions consists of the following equations: ${ }^{17}$

$$
\begin{aligned}
\hat{C}_{t} & =\mathcal{E}_{t} \hat{C}_{t+1}-\frac{1}{\sigma}\left(\hat{\imath}_{t}-\mathcal{E}_{t} \hat{\pi}_{H, t+1}-\alpha\left(\hat{S}_{t+1}-\hat{S}_{t}\right)\right) \\
\hat{\pi}_{H t} & =\beta \mathcal{E}_{t} \hat{\pi}_{H t+1}+\lambda\left(\sigma \hat{C}_{t}+\phi \hat{Y}_{t}+\alpha \hat{S}_{t}-(\phi+1) \hat{A}_{t}\right)+\eta_{t}, \\
\hat{Y}_{t} & =(1-\alpha)(1-\gamma) \hat{C}_{t}-\eta \alpha(\alpha-2)(1-\gamma) \hat{S}_{t}+\alpha(1-\gamma) \hat{C}_{t}^{*}+\gamma \hat{G}_{t}, \\
\hat{\imath}_{t} & =\hat{\imath}_{t}^{*}-\hat{E}_{t}+\mathcal{E}_{t} \hat{E}_{t+1}-\delta \hat{d}_{t} \\
\beta \hat{d}_{t} & =\hat{d}_{t-1}+\hat{Y}_{t}-\alpha(1-\gamma) \hat{S}_{t}-\gamma \hat{G}_{H, t}-(1-\gamma) \hat{C}_{t} \\
\hat{E}_{t} & =\hat{S}_{t}-\hat{p}_{H, t}+\hat{p}_{t}^{*} \\
\hat{p}_{H, t} & =\hat{p}_{H, t-1}+\hat{\pi}_{H, t} .
\end{aligned}
$$

where $\lambda=(1-\theta)(1-\theta \beta) / \theta$. Optimal decisions of the household are described by the Euler equation (16) and by a standard New Keynesian Phillips curve (17). The national income identity equation (18) states that domestic output is positively related to government spending and consumption of the rest of the world. It is negatively related to improvements in the terms of trade $(S \downarrow)$, because $\alpha<1$ and $\eta>0$. An improvement in the terms of trade will lead to a shift in household's consumption towards foreign goods. The expression in front of the terms of trade can be interpreted as an 'expenditure switching' factor which is increasing in $\eta$. The described setup allows for deviations from the uncovered interest parity (equation (19)). There is a time varying risk-premium that depends on both the net foreign asset position of the country $\hat{d}_{t}$ and a cost of bond holdings $\delta$. This risk premium could be positive or negative depending on the home country being a borrower or a lender in the international assets market. Owing to the incomplete market setting the Euler equation is not sufficient to determine the dynamics of aggregate demand. We also need equation (20) to pin down the dynamics of the net foreign assets, where the portfolio cost parameter $\delta$ influences the evolution of the net foreign assets through its impact on the terms of trade. We also include definitions of terms of trade (21) and the price level (22).

The private sector rational expectations equilibrium consists of the plan $\left\{\hat{C}_{t}, \hat{\pi}_{H t}, \hat{d}_{t}, \hat{Y}_{t}, \hat{\imath}_{t}, \hat{E}_{t}, \hat{p}_{H, t}\right\}$

satisfying equations (16)-(22), given the policy $\left\{\hat{\imath}_{t}\right\}$, the exogenous processes $\left\{\eta_{t}, \hat{A}_{t}, \eta_{t}^{*}, \hat{A}_{t}^{*}\right\}$ (as $\left\{\hat{C}_{t}^{*}, \hat{\pi}_{t}^{*}, \hat{\imath}_{t}^{*}\right\}$ are functions of $\left\{\hat{A}_{t}^{*}, \eta_{t}^{*}\right\}$, see equations (11)-(15)) and initial conditions $\hat{d}_{0}$.

\subsubsection{Timing of Events}

The sequence of events and actions within a period is as follows. In the first stage of every period $t$ the state $\hat{d}_{t-1}$ is known and shock $\eta_{t}$ realizes. Then the policymaker chooses the value of $\hat{\imath}_{t}$. The policymaker knows the state $\hat{d}_{t-1}$ and takes the process by which private agents behave as given. After the policymakers moved, in the next stage the private sector adjusts its choice variables $\pi_{t}$ and $\hat{C}_{t}$. The optimal $\pi_{t}, \hat{C}_{t}$, policy $\hat{\imath}_{t}$ and the nominal exchange rate $\hat{E}_{t}$ result in the new level of $\hat{d}_{t}$ by the beginning of the next period $t+1$.

\footnotetext{
${ }^{17}$ Note that we define analogous to Benigno $(2001) \hat{d}_{t}$ as $\frac{d_{t}-d}{Y}$ and $\delta=-\phi^{\prime}(d) Y$.
} 


\subsection{Monetary Policy}

\subsubsection{Social Welfare}

We assume that the central bank uses nominal short-term interest rate $\hat{\imath}_{t}$ as an instrument. We assume that the social welfare function is well captured by the following discounted quadratic loss function:

$$
W_{t}^{\Pi}=\frac{1}{2} \sum_{s=t}^{\infty} \beta^{s-t}\left(\hat{\pi}_{H s}^{2}+\omega\left(\hat{Y}_{s}-\hat{Y}_{s}^{n}\right)^{2}\right),
$$

where $\omega=\lambda / \varepsilon$ and $\hat{Y}_{s}^{n}$ is the natural rate of output (in the flexible price equilibrium without mark up shocks). This welfare function has been shown by Woodford (2003a), Ch. 6, to approximate the aggregate of individual utility functions in a closed economy model with complete financial markets (with $\delta=0$ ). In our model, this approximation will not hold up to the second order and so our policy objective function is to some degree ad hoc. However, as King and Wolman (2004) and Blake and Kirsanova (2008) argue, multiplicity under discretion is not a consequence of a particularly 'unfortunate' form of social welfare, but rather a general property of discretionary policy, as the private sector and the policymaker make decisions based on forecast of each other's actions. ${ }^{18}$ In what follows we simply refer to this objective as to the social objective. We also label (23) as 'inflation targeting regime'. Note that we do this for convenience and not to take a stand on the optimality or the precise nature of inflation targeting regimes as practiced in real life.

\subsubsection{The benchmark Ramsey allocation}

The Ramsey allocation takes into account the presence of distortions, as summarised by constraints (16)-(22). Specifically, the Ramsey allocations in the LQ framework solves

$$
\min _{\left\{i_{t}\right\}} \frac{1}{2} \mathcal{E}_{t} \sum_{s=t}^{\infty} \beta^{s-t} W_{s}^{\Pi}
$$

subject to constraints $(16)-(22)$ for all $t \geq 0 .{ }^{19}$

The Ramsey allocation requires commitment to policy. In what follows we term the solution as the commitment solution. We use the commitment solution as the benchmark case for welfare evaluations.

\footnotetext{
${ }^{18}$ Note that we also abstract from the terms of trade externality (e.g. Obstfeld and Rogoff (1998), Corsetti and Pesenti (2001)). In an open economy the policymaker may have the incentive to influence the terms-of-trade in a way benifical to domestic households. Assuming fully optimal time-inconsistent policy, De Paoli (2009a) shows that in a small open economy an improvement in the terms-of-trade can increase the welfare of the households, if domestic and foreign goods are close substitutes. In this case domestic households consume more imported goods and can therefore reduce their labor effort without a corresponding fall in consumption levels. This derivation, however, is not suitable for our model with discretionary policy and we prefer to use a more traditional alternative. The volatility of the terms of trade does affect welfare but only because it affects the volatility of output gap.

${ }^{19}$ Note that the central bank uses the interest rate gap $i_{t}=\hat{\imath}_{t}-\hat{\imath}_{t}^{n}$ as its instrument.
} 


\subsubsection{Nominal Exchange Rate Targeting under Discretion}

We also study implications of partial nominal exchange rate targeting represented by the following policy objective function

$$
\frac{1}{2} \sum_{s=t}^{\infty} \beta^{s-t}\left(\hat{\pi}_{H s}^{2}+\omega\left(\hat{Y}_{s}-\hat{Y}_{s}^{n}\right)^{2}+\omega_{e} \hat{E}_{s}^{2}\right),
$$

where we impose an additional weight on stabilisation of nominal exchange rate around the steady state value.

If $\omega_{e}=0$ then we have the standard inflation targeting regime with the policy objective $W_{t}^{\Pi}$. We shall study it as one extreme case.

If $\omega_{e}$ is infinitely large, it is equivalent to have just one target, the nominal exchange rate:

$$
\frac{1}{2} \sum_{s=t}^{\infty} \beta^{s-t} \hat{E}_{s}^{2} .
$$

We shall label this scenario as 'soft peg' and study it as another important extreme case of partial nominal exchange rate targeting (24). This targeting regime has some similarities with a fixed exchange rate regime. In particular, this regime assumes that the policymaker announces the target, perhaps within a corridor (which we do not model as binding in any way, so it does not affect expectations of the private sector) and uses the short term interest rate to keep the exchange rate on target. The exchange rate, however, is allowed to deviate from the target, although such deviations are costly. We distinguish this regime from the 'hard peg' where the monetary policymaker is prepared to sell any quantity of reserves at a given price to keep the exchange rate exactly on target. The hard peg cannot be modelled with a quadratic loss function - any regime with quadratic loss function allows (costly) deviations from the parity while the hard peg regime does not. Another way to model fixed exchange rate regime could be to assume a simple interest rate rule that feeds back on exchange rate deviations from their target (see e.g.Galí and Monacelli (2005)). Deviations from the target are possible under this regime, but such rules require credible commitment which may not always be possible in a developing country.

\subsection{Calibration}

We set the subjective discount rate $\beta=0.99$, which implies a steady state real interest rate slightly above $4 \%$ (in a quarterly model). Following Beetsma and Jensen (2004) we set $\varphi=3$, which implies the Frisch-elasticity of labour supply of $1 / 3$. The degree of price stickiness is given by $\theta=0.75$, so price contracts last on average for one year (see e.g. Smets and Wouters (2003)). In line with Galí and Monacelli (2005) we set the steady state markup $\mu=1.2$, which implies that the elasticity of substitution $\epsilon$ is equal to 6 ; we also set the government share of output $\gamma$ as 0.25. This value is in line with Galí and Monacelli (2005) and roughly consistent with European data. In the benchmark calibration we assume a unitary coefficient of risk sharing $\sigma$ implying a $\log$ utility function. Following Benigno (2009) we set $\delta=0.01$ which implies a 10 basis point spread of the domestic interest rate over the foreign one. For the elasticity of substitution we assume $\eta=3$ (Obstfeld and Rogoff (1998)). Finally, cost push shocks are assumed to be i.i.d. and technology shocks follows the following $\operatorname{AR}(1)$ process with persistence parameter $\rho_{a}=\rho_{a^{*}}=0.8$. The standard deviation of cost push shock is 0.005 and of a productivity shock it is 0.0075 . 


\section{Discretionary Equilibria}

We start with the benchmark inflation targeting regime and discuss arising discretionary equilibria. We then continue with the extreme case of a 'soft peg' as this is the most simple setting to discuss problems that might arise if a country targets exchange rate. We intentionally ignore all other possible targets of the central bank for simplicity and clarity. We then check for robustness of our results. Finally we investigate the intermediate case of 'partial' exchange rate targeting where the central bank puts some weight in its loss function to exchange rate deviations additionally to the standard inflation targeting regime.

\subsection{Inflation Targeting Regime}

In the inflation targeting regime the policymaker uses the social welfare function $W_{t}^{\Pi}$. The evolution of the economy can be rewritten as:

$$
\begin{aligned}
\beta \hat{d}_{t}= & \hat{d}_{t-1}-\alpha(1-\gamma) \hat{C}_{t}+\alpha(1-\gamma)(\eta(2-\alpha)-1) \hat{S}_{t}+\alpha(1-\gamma) \hat{C}_{t}^{*}, \\
\hat{\imath}_{t}= & \mathcal{E}_{t} \hat{S}_{t+1}-\hat{S}_{t}+\mathcal{E}_{t} \pi_{H, t+1}-\delta \hat{d}_{t}+\hat{\imath}_{t}^{*}, \\
\hat{C}_{t}= & \mathcal{E}_{t} \hat{C}_{t+1}-\frac{1}{\sigma}\left(\hat{\imath}_{t}-\mathcal{E}_{t} \hat{\pi}_{H, t+1}-\alpha\left(\mathcal{E}_{t} \hat{S}_{t+1}-\hat{S}_{t}\right)\right), \\
\hat{\pi}_{H t}= & \beta \mathcal{E}_{t} \hat{\pi}_{H t+1}+\lambda(\sigma+\phi(1-\alpha)(1-\gamma)) \hat{C}_{t}+\lambda \alpha(1+\phi \eta(2-\alpha)(1-\gamma)) \hat{S}_{t} \\
& +\lambda \phi \alpha(1-\gamma) \hat{C}_{t}^{*}+\lambda \phi \gamma \hat{G}_{t}-\lambda(\phi+1) \hat{A}_{t}+\eta_{t},
\end{aligned}
$$

where we substituted all static equations and left only dynamic relationships.

There is only one predetermined endogenous state variable, net foreign assets $\hat{d}_{t-1}$, three nonpredetermined endogenous state variables, $\hat{C}_{t}, \hat{\pi}_{H t}$ and $\hat{S}_{t}$, one instrument $\hat{\imath}_{t}$, and two shocks, $\eta_{t}$ and $\eta_{t}^{*}$, whereby $\hat{\imath}_{t}^{*}, \hat{C}_{t}^{*}$ and $\pi_{t}^{*}$ are all functions of $\eta_{t}^{*}$.

\subsubsection{The Two Equilibria}

The baseline calibration leads to two discretionary equilibria under the policy of inflation targeting. The upper panel of Figure 1 demonstrates, that following an initial current account deficit the economy can follow one of the two transition paths, both of which satisfy the first-order conditions for optimality and time-consistency. They correspond to the two IE-stable discretionary equilibria described in the Appendix B. The corresponding adjustment paths are plotted using either solid or dashed lines.

When the economy starts out of the steady state with a negative net foreign assets position the household will wish to adjust. The household will choose consumption and prices, taking into account the future paths of the interest rate as well as the state of the economy. The policymaker will use its policy instrument, the interest rate, to help to steer the economy back to the steady state; he will choose the interest rate optimally, based on the forecast of the reaction of the household to the policy and to the state of the economy.

Choosing the adjustment paths the household can foresee that the negative position in net foreign assets can be closed either quickly, if the interest rate falls sharply with a consequent depreciation of domestic currency, trade surplus and accumulation of net foreign assets, or it can be closed slowly if the interest rate rises only slightly with only a small consequent fall in 
consumption and therefore a slow accumulation of net foreign assets. Depending on whether adjustment is expected to be slow or fast, the private sector will set corresponding expectations and appropriate prices. It will be optimal for the policymaker to validate the beliefs that will prevail. Two equilibria arise.

These different adjustment paths can be explained by the multiplicity of policy-induced private sector equilibria, see Blake and Kirsanova (2008). Essentially, for every policy there is more than one locally optimal response of the private sector, which is of course, conditional on the forecast of future policy. In order to understand how multiplicity arise we can look at the role which consumption and the terms of trade play in the determination of the law of motion for marginal costs. After some algebra, the deterministic component of the marginal cost can be written out as:

$$
\widehat{m c}_{t}=(\sigma+\phi(1-\alpha)(1-\gamma)) \hat{C}_{t}+\alpha(1+\phi \eta(2-\alpha)(1-\gamma)) \hat{S}_{t} .
$$

It is apparent that consumption and the terms of trade are strategic complements in the control of inflation. When a positive cost-push shock hits the system the policymaker rises the interest rate and consumption is cut. Terms of trade improve. Households will use the current account to smooth consumption and decumulate net foreign assets The improved terms of trade reduce marginal cost even further. In other words, following an interest rate increase, the effect of consumption on the terms of trade reinforces the effect of the interest rate on the terms of trade, so we have a strategic complementarity as defined, for example, in Cooper and John (1988). Multiplicity of the policy-induced private sector equilibria becomes a likely outcome: household may choose to react in several possible ways - here they are 'slow' and 'fast' - each of them is consistent with a given policy forecast. Of course, the policymaker will react differently in response to different household actions, but the household will update their forecasts of policy in both scenarios. We end up with two discretionary equilibria and the policymaker validates beliefs in each particular equilibrium. In presence of the two equilibria, coordination failure happens: the household and the private sector can choose any of the two. A sunspot decides which one will realise as we discuss in more details in the next section.

In order to illustrate the mechanism in a stochastic setting, we plot the impulse responses to a unit cost push shock in the home economy in the middle panel of Figure 1. The shock is absorbed via a temporary fall in home output and consumption and by an initial jump in home inflation. The central bank fights inflation through an increase in the interest rate. After the shock, output and consumption converge to their steady states and the price level converges as well to the steady state through periods of (a very small) deflation. Households use the current account as a risksharing tool and sell foreign assets to dampen the decline in consumption. Therefore the country will run a current account deficit. The fall in output improves the home country terms-of-trade. As described above the baseline calibration produces two stable discretionary equilibria. The slow adjustment solution to the problem is to raise the nominal interest rate sharply, resulting in a fall in demand, low inflation and a sharp appreciation of domestic currency. As a result the value of net foreign assets will be sharply reduced first and then gradually accumulated back to the initial level while the other variables stay close to their equilibrium levels in subsequent periods.

If the economy is hit by an external cost-push shock, the foreign interest rate is raised, foreign consumption falls, the terms of trade improve and the value of foreign bonds increases. The home interest rate is raised in both regimes and therefore enforces the decline in consumption. In the 
slow regime it is raised by less. This results in a lower decline of consumption and therefore a stronger accumulation of net foreign assets, a small deflation and still depreciated terms of trade. When the interest rate is moved down below the baseline this results in higher inflation, small improvement of the terms of trade and still a higher foreign asset position. The accumulated net foreign assets converge slowly to the steady state in the second period and the consequent appreciated terms of trade gradually reduces inflation back to the steady state.

In the fast regime the interest rate is raised by much, the nominal exchange rate appreciate and consumption falls by much. As a result the terms of trade appreciate, net foreign assets accumulate and domestic inflation becomes negative. The positive position in net foreign assets causes consequent depreciation of the terms of trade, high inflation and overall price level stability.

Note that the nominal exchange rate does not converge back to its initial value in any of the stochastic regimes. The terms of trade are stabilised, but both price level and the nominal exchange rate are unit root variables.

The responses to a positive cost-push shock for both cases look as if they were produced by the application of the classic problem of 'dry' and 'wet' policymakers (Barro and Gordon (1983)), adapted for a dynamic setting (see e.g. the discussion of the conservative central bank proposal in a dynamic setting in Clarida et al. (1999), p. 1677). In both scenarios, the interest rate rises in response to the shock, but in one scenario it rises by much more. As a result, and as in the 'dry' versus 'wet' example, we have the bigger fall in output and less inflation in the first scenario than in the second. However, rather differently from the classic problem, we have two locally optimal responses under identical policy objectives.

Based on our observations, the two discretionary solutions can also be seen as the product of 'seemingly patient' respectively 'seemingly impatient' policymakers, with their degree of patience determined by the speed of the adjustment process of the economy back to the steady state. This distinction has nothing to do with the discount factor in the objective functions, as they remain the same. As we argue next, households/ firms make decisions based on the forecast of future policy: They either decide to bear or not the cost of adjustment. The private sector, thus, chooses the equilibrium. The policymaker has no choice but to validate the forecast. We will investigate this in the following section in more detail.

\subsubsection{Policy traps and equilibrium selection}

Table 1 reports the welfare losses for the baseline calibration for different regimes. We claim that despite there is a clear difference in welfare ranking of the two regimes, the discretionary policymaker is unable to choose the one which yields the highest welfare. Multiplicity can only exist if there is a multiplicity of beliefs, shared by the private sector and the policymaker, about the future course of policy. The discretionary policymaker is unable to manipulate the private sector's beliefs in order to choose the best equilibrium globally. To understand this, it is instructive to compare what is happening in commitment and discretionary equilibria. Under commitment the policymaker is able to manipulate the private sector's expectations along the whole future path, and thus, by implication, is able to choose the best path for all variables including beliefs. The discretionary policymaker is only able to manipulate private sector beliefs within a single period $t$. This is because the discretionary policymaker acts as an intra-period Stackelberg leader, see Cohen and Michel (1988), sections 4 and 5. However, the policy choice in period $t$ has to be consistent 
DETERMINISTIC MODEL

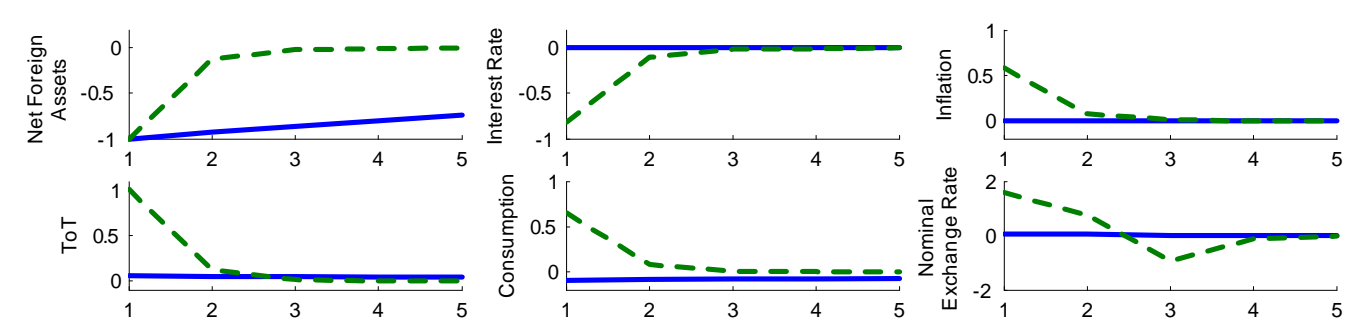

STOCHASTIC MODEL: DOMESTIC COST PUSH SHOCK

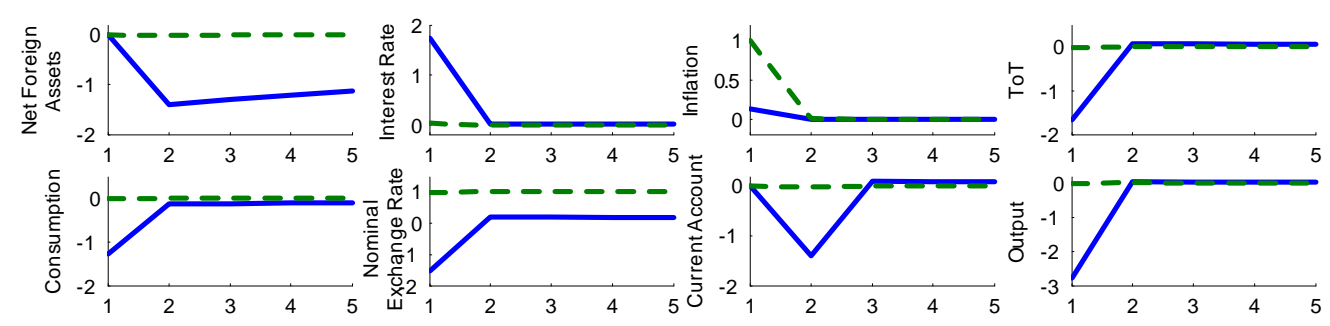

STOCHASTIC MODEL: EXTERNAL COST PUSH SHOCK

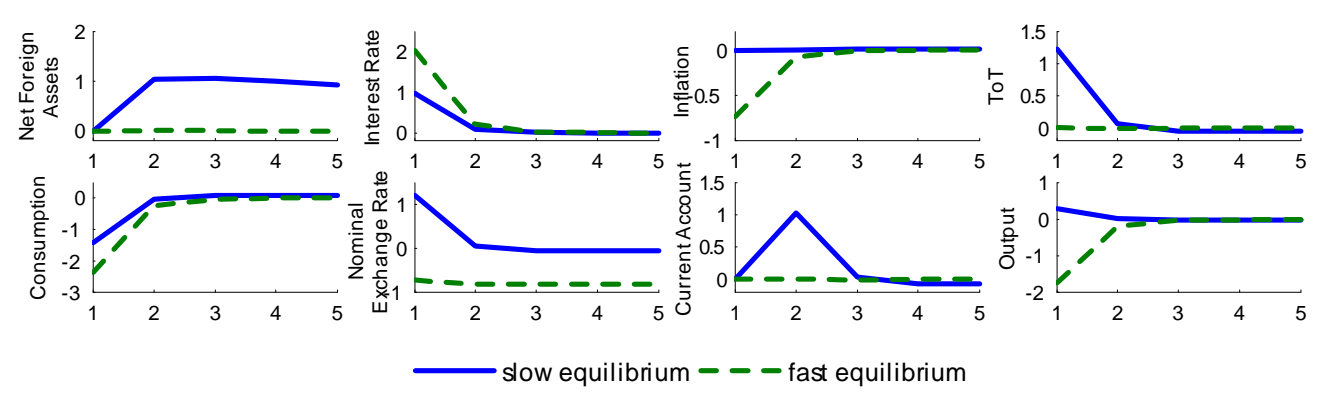

Figure 1: Inflation Targeting 


\begin{tabular}{lcc}
\hline \hline Policymaker & Policy Equilibrium & Loss \\
\hline 'Seemingly Dry' and 'Patient' & With slow adjustment & 0.278 \\
'Seemingly Wet' and 'Impatient' & With fast adjustment & 3.419 \\
Reputational & Fully Optimal & 0.250 \\
\hline \hline
\end{tabular}

Table 1: Social Welfare Loss, \% of steady state consumption.

with (or conditional on) beliefs set in previous periods if there are endogenous predetermined state variables in the model. These past-period beliefs cannot be changed retrospectively. Once they are set their effect is long-lasting and so at time $t$ the policymaker has to take into account the future evolution of the economy which has been affected by beliefs set prior to period $t$. (Again, unlike the case of commitment there is no 'period 0' when a policymaker has the power to 'change everything' irrespective of history.) In this sense, the private sector 'traps' the policymaker in a particular equilibrium.

In our model the net foreign asset position is an endogenous predetermined state variable. Their evolution is determined by consumption/ output and the terms of trade (and thus by price-setting behaviour). Consumption and prices are chosen based on the forecasted path of all variables including foreign assets. The household (who owns all firms too) is either willing or not to adjust prices and consumption in response to a shock. Its choice depends on beliefs about how quickly any adjustment will happen, and only on this. The household does not face such a choice in a world with perfect financial markets, i.e. with no predetermined endogenous variables. In this case the economy once disturbed converges back to the steady state within a single period. All monetary policy can do is to reduce the amplitude of the immediate reactions of economic variables to shocks. The feedback coefficient of the policy rule on the observed shocks is responsible for this reduction. If there are predetermined variables in the system, then policy can also reduce the half-life of the effects of shocks already in the system. This stabilization effectively reduces the size of the non-explosive non-zero eigenvalues of the system under control. The feedback coefficients of the endogenous predetermined variables are responsible for this.

These two tasks are completely orthogonal to each other, i.e. two rules which only differ in the feedback coefficients on shocks will ensure the same half-life, and two rules which only differ by feedback coefficients on predetermined (dynamic) states will identically reduce the amplitude of concurrent shocks. The private sector can perceive the policymaker as either being 'quick' or 'slow' to stabilize the economy. These expectations decide about the first-period position in foreign assets. In turn, these expectation affect the economy more than one period into the future, as they are embedded in the dynamics of the net foreign assets. Any implied future dynamics of the economy are necessarily taken into account by future policy. The impulse responses to a cost-push shock in Figure 1 certainly resemble a policymaker that is either 'dry/patient' or 'wet/impatient'. However, this is because the policymaker has to use the initial movement in interest rates to offset private sector perceptions of bringing back the economy either 'quick' or 'slow' to its steady state; the policymaker has to stick to this policy in the future.

In what follows we will term these equilibria as quick/fast and slow. 


\subsection{Nominal Exchange Rate Targeting}

We start with the second extreme case, the 'soft peg'. We completely ignore other targets, which may not be realistic, but the resulting regime is a useful simplification to illustrate our main point. ${ }^{20}$ Under the 'soft peg', the reduced form system in log-linearised form can be written as:

$$
\begin{aligned}
\beta \hat{d}_{t}= & \hat{d}_{t-1}-\alpha(1-\gamma) \hat{C}_{t}+\alpha(1-\gamma)(\eta(2-\alpha)-1)\left(\hat{E}_{t}+\hat{p}_{H, t}-\hat{p}_{t}^{*}\right)+\alpha(1-\gamma) \hat{C}_{t}^{*}, \\
\hat{\imath}_{t}= & \hat{\imath}_{t}^{*}+\mathcal{E}_{t} \hat{E}_{t+1}-\hat{E}_{t}-\delta \hat{d}_{t}, \\
\hat{C}_{t}= & \mathcal{E}_{t} \hat{C}_{t+1}-\frac{1}{\sigma}\left(\hat{\imath}_{t}-(1-\alpha) \mathcal{E}_{t} \hat{\pi}_{H t+1}-\alpha\left(\mathcal{E}_{t} \hat{E}_{t+1}-\hat{E}_{t}\right)\right), \\
\hat{\pi}_{H t}= & \beta \mathcal{E}_{t} \hat{\pi}_{H t+1}+\lambda(\sigma+\phi(1-\alpha)(1-\gamma)) \hat{C}_{t}+\lambda \alpha(1+\phi \eta(2-\alpha)(1-\gamma))\left(\hat{E}_{t}+\hat{p}_{H, t}-\hat{p}_{t}^{*}\right) \\
& +\lambda \phi \alpha(1-\gamma) \hat{C}_{t}^{*}+\lambda \phi \gamma \hat{G}_{t}-\lambda(\phi+1) \hat{A}_{t}+\eta_{t}, \\
\hat{p}_{H, t}= & \hat{p}_{H, t-1}+\hat{\pi}_{H, t} .
\end{aligned}
$$

Different from the version in the previous section there are two predetermined endogenous state variables: net foreign assets and the price level, $\hat{d}_{t-1}$ and $\hat{p}_{H, t-1}$. The non-predetermined variables are $\hat{E}_{t}, \hat{\pi}_{H, t}$ and $\hat{C}_{t}$. There are two shocks, $\eta_{t}$ and $\eta_{t}^{*}$, whereby $\hat{\imath}_{t}^{*}, \hat{C}_{t}^{*}$ and $\pi_{t}^{*}$ are all functions of $\eta_{t}^{*}$. Unlike under inflation targeting, we cannot substitute the nominal exchange rate and the price level into only one variable, the terms of trade. We have to account for the dynamics of the nominal exchange rate separately because it is the goal variable of the policymaker.

\subsubsection{The 'soft peg'}

We start with the claim that under the 'soft peg' it is possible to keep the exchange rate on target all the time. ${ }^{21}$ Suppose we are in the deterministic version of the model and the economy starts with an excessive foreign debt. This scenario is plotted in the upper panel of Figure 2 by the solid line. In order to steer the economy back to the steady state the policymaker moves the interest rate based on the forecast of the future net foreign asset position and of the expected future depreciation. If there is a common belief that the nominal exchange rate will remain in the steady state in the future, it will be optimal for the policymaker to raise the interest rate by little, to offset $\delta \hat{d}_{t}$. There will be slight fall in consumption and inflation. As a result, the small increase in savings will dominate the effect of the improvement in the terms of trade on the net foreign assets. Net foreign assets will grow by little in the next period and this will require a small positive interest rate until the process converges to the steady state. The nominal exchange rate will remain in the steady state, i.e. the forecast will be validated by the policymaker.

However, the equilibrium with stable nominal exchange rate is not the only one. ${ }^{22}$ The second possible adjustment path is plotted in the upper panel of Figure 2 with a dashed line. Following an initial negative position in foreign debt and if there is a commonly shared belief in future appreciation of the nominal exchange rate, it is optimal for the central bank to reduce interest rate sharply, causing immediate currency depreciation and a rise in consumption and inflation.

\footnotetext{
${ }^{20}$ We study at the general case of nominal exchange rate targeting below in Section 3.2.2.

${ }^{21}$ This is a standard result in this strand of literature, see e.g. Galí and Monacelli (2005).

${ }^{22}$ The procedure to find all equilibria is the same as in the case of inflation targeting which we discuss in details in Appendix B.
} 
DETERMINISTIC MODEL
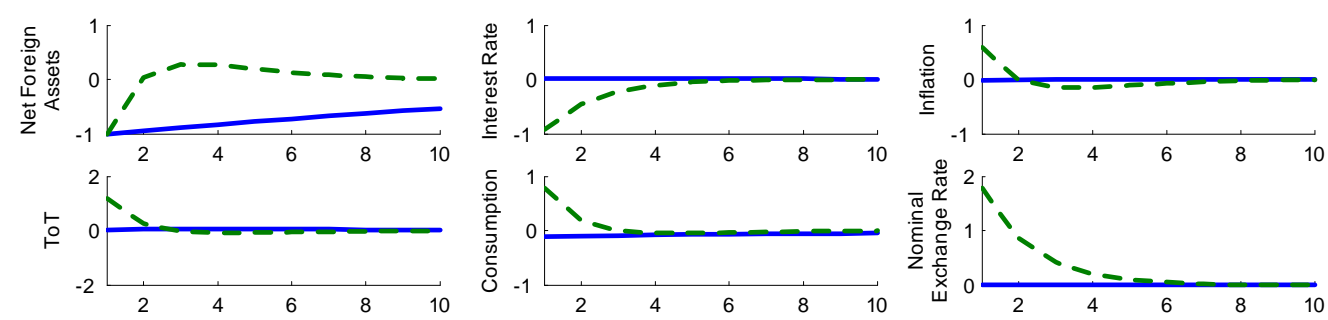

STOCHASTIC MODEL: DOMESTIC COST PUSH SHOCK

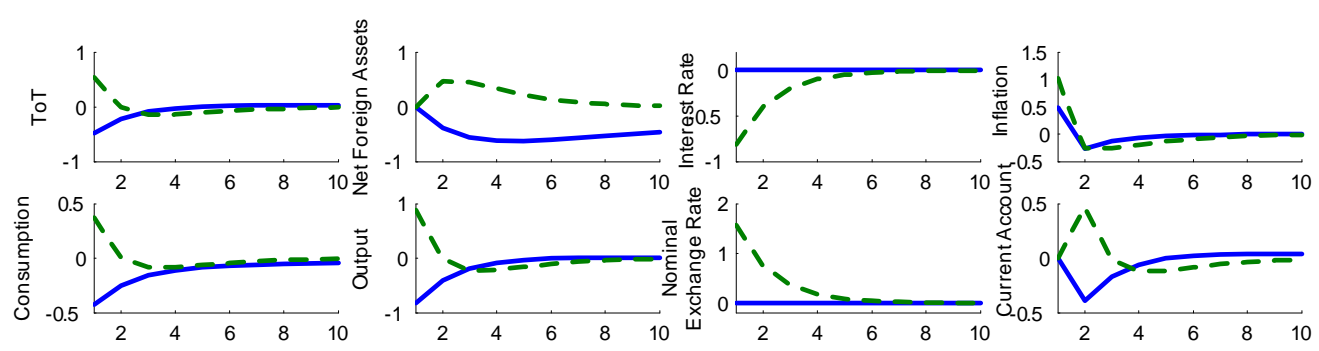

STOCHASTIC MODEL: EXTERNAL COST PUSH SHOCK

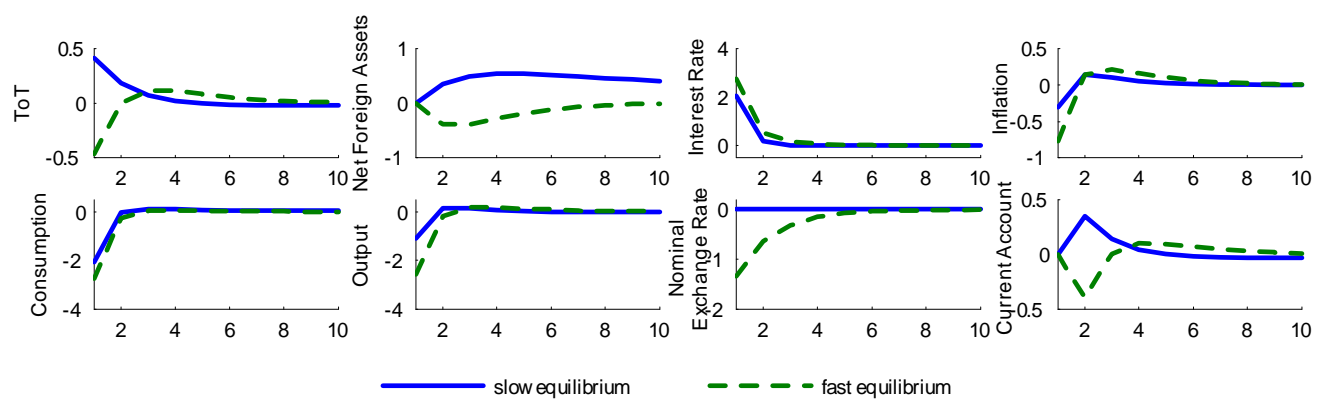

Figure 2: Exchange Rate Targeting 
The terms of trade worsen and savings rise. This results in quick accumulation of foreign assets. A higher level of foreign assets pushes the optimal interest rate to fall even further. In other words, there is a complementarity between the interest rate and foreign assets: a reduction in the interest rate raises foreign assets that require again a lower equilibrium interest rate. With complementarities, multiplicity of equilibria becomes a likely outcome. Therefore it is not surprising that this outcome has realised in this model.

The 'soft peg' requires that the price level returns to its initial level. Therefore we should observe inflation overshooting and, indeed, this is achieved in the second equilibrium by lowering the interest rate sharply. The decline in the interest rate generates an increase in consumption and a depreciation of the terms of trade which both generate an increase in the value of the stock of net foreign assets above its steady state level. When the interest rate is raised back to its baseline level, this higher value of net foreign assets creates an additional pressure on the terms of trade. The terms of trade overshoot, improve and stay below their baseline level for a number of periods. The effect on marginal cost generates inflation overshooting and price level stability. The nominal exchange rate is stabilised at its initial level.

Despite it is commonly suggested that currency pegging is an efficient way to import low and stable inflation, it is apparent that in the case of a 'soft peg' the implied volatility of the nominal exchange rate and domestic inflation in the worst regime is higher than it is in the case of inflation targeting. This is not surprising: these are two 'second-best' scenarios, and there cannot be any a priori ranking between them. Also, the welfare minimisation in the 'soft peg' case assumes that both predetermined states (foreign assets and prices) can be out of the steady state so their volatility should be minimised 'on average', see Currie and Levine (1985). This is contrary to the inflation targeting regime where only one predetermined state exists.

The middle panel of Figure 2 plots the impulse responses to a domestic cost push shock. In the slow equilibrium inflation is accommodated: the interest rate is only marginally raised in response to the shock, and consumption falls only slightly. The terms of trade improve and the net foreign wealth loses in value. The negative net foreign assets position pushes the interest rate even further and consumption remains substantially below the baseline. This fall in consumption becomes large and long enough to reduce the marginal cost below the baseline, so inflation will fall sharply, the terms of trade will worsen and net foreign assets start to accumulate again. (Inflation falls sufficiently low to ensure price level stability.) The same mechanism then works to steer the economy back to the steady state.

In the fast equilibrium inflation is also accommodated with a fall in the interest rate. If there is a common belief that the currency will appreciate in the future it is optimal for the policymaker to lower the interest rate now, create an immediate depreciation and worsen the terms of trade, which all leads to a rise in the real value of foreign assets. The expected appreciation drives private consumption down below the baseline, marginal costs follow and inflation is reduced below the baseline. The terms of trade improve and households start to decumulate net foreign assets. There will be less pressure to keep the interest rate low and the economy gradually converges back. A substantial inflation overshooting guarantees price level stability and the nominal exchange rate is on target.

Note that the existence of the second equilibrium does not depend on any credibility issues: discretionary policy is credible by construction, the policymaker has never promised to keep the nominal exchange rate on target. The policymaker has only promised to minimise volatility 


\begin{tabular}{lcc}
\hline \hline Policymaker & Policy Equilibrium & Loss \\
\hline Good & With slow adjustment & 1.457 \\
Bad & With fast adjustment & 5.770 \\
Reputational (soft peg) & Fully Optimal & 1.457 \\
\hline \hline
\end{tabular}

Table 2: Social welfare Loss under Exchange Rate Targeting, \% of steady state consumption

around the target. Therefore, it is acceptable to have deviations from the target as soon as all agents know the target. The possibility of 'future appreciation', i.e. different speeds of convergence towards the steady state, generates the second equilibrium.

The lower panel in Figure 2 demonstrates both equilibria if there is an external cost push shock. Again, it is possible to offset the shock completely. If there is a common belief that the nominal exchange rate will remain on target, the interest rate can be raised in order to offset the effect of the foreign interest rate on the economy. Consumption will fall, savings increase and net foreign assets will rise. As the terms of trade have become worse after the foreign cost-push shock, inflation will drive up in the second period. Consumption will rise and savings will fall so net foreign assets start to decumulate. A consequent improvement in the terms of trade ensures that the process of convergence is slow.

If, following an external cost push shock and a rise in the foreign interest rate, there is a common belief that the currency can depreciate in the future, then the policymaker has to raise the interest rate by more than if the currency is expected to be on target. This results in an immediate appreciation of the currency and an improvement in the terms of trade. The terms of trade effect dominates all other effects on the net foreign assets position - foreign assets lose in value. The improved terms of trade result in higher marginal costs and an higher inflation. The low real interest rate leads to an increase in consumption, so foreign assets start to accumulate and the economy eventually converges back to the steady state.

Table 2 reports social losses computed in assumption that the economy starts in the steady state and is then hit by internal and external cost-push and productivity shocks. These shocks are distributed as explained in Section 2.7. The 'slow' discretionary equilibrium is able to replicate the commitment equilibrium under the 'soft peg'. In the 'fast' equilibrium the loss is substantially higher.

\subsubsection{Partial Exchange Rate Targeting}

Suppose a country with true flow social welfare metric

$$
W_{t}^{\Pi}=\hat{\pi}_{H t}^{2}+\omega_{y}\left(\hat{Y}_{t}-\hat{Y}_{t}^{n}\right)^{2}
$$

decides to put an additional weight on nominal exchange rate targeting (provided that the anchor country pursues price stability) and chooses

$$
W_{t}=\hat{\pi}_{H t}^{2}+\omega_{y}\left(\hat{Y}_{t}-\hat{Y}_{t}^{n}\right)^{2}+\omega_{e} \hat{E}_{t}^{2}
$$

as its flow objective. Table 3 reports four results. In every line we measure the implied social loss as a function of $\omega_{e}$. 

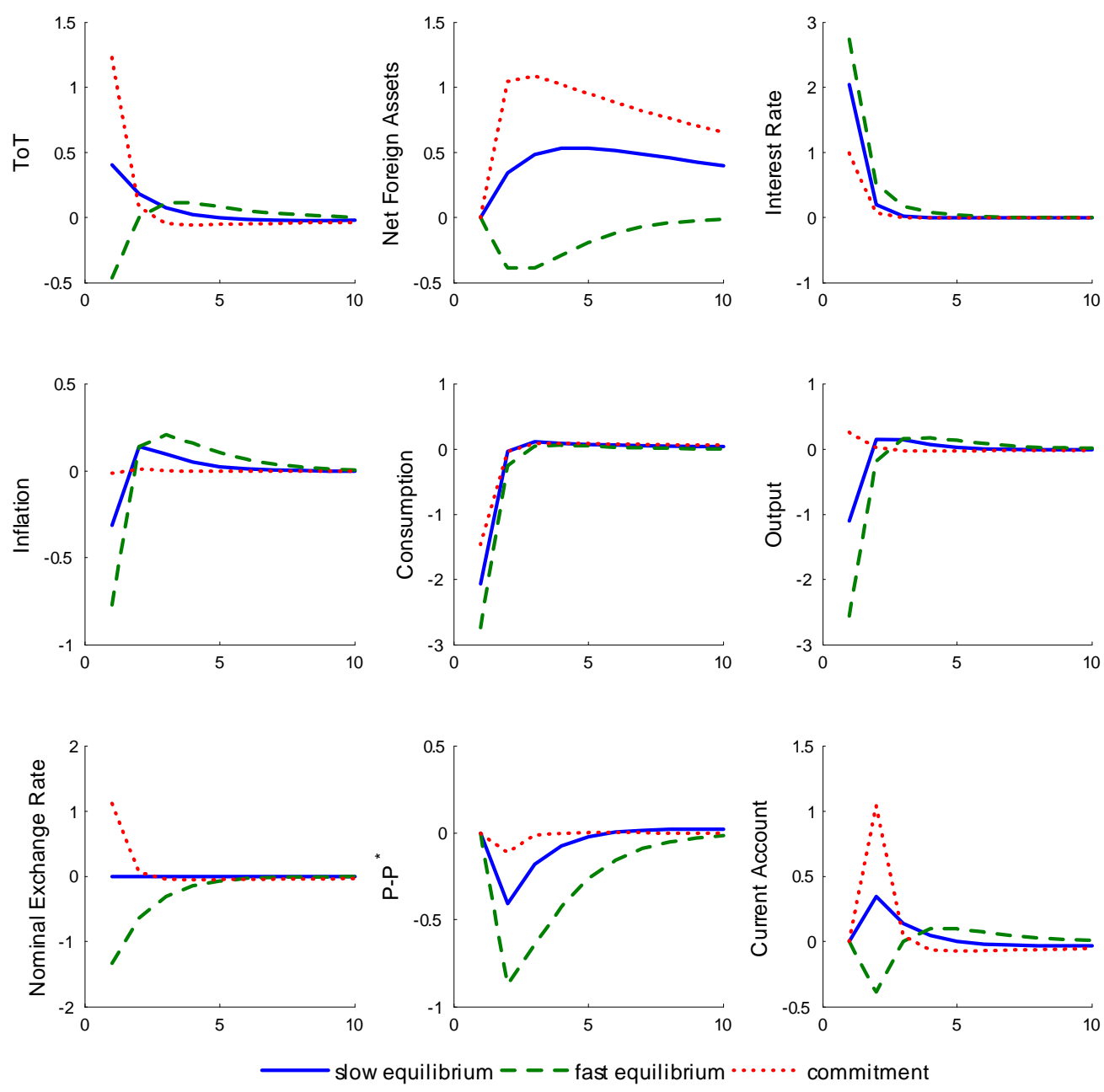

Figure 3: Partial Exchange Rate Targeting 


\begin{tabular}{lccccccccccc}
\hline \hline $1 / \omega_{e}$ & 0.0 & 0.1 & 0.5 & 1.0 & 5.0 & 10 & 20 & 30 & 40 & 50 & $\infty$ \\
$\omega_{e}$ & $\infty$ & 10 & 2 & 1.0 & 0.2 & 0.1 & 0.05 & 0.033 & 0.025 & 0.02 & 0 \\
$W^{S}$ & 1.457 & 1.432 & 1.340 & 1.238 & 0.759 & 0.527 & 0.376 & 0.328 & 0.308 & 0.297 & 0.278 \\
$W^{F}$ & 5.770 & 5.765 & 5.743 & 5.718 & 5.592 & 5.522 & 5.486 & 5.503 & 5.546 & 5.609 & - \\
$W^{\Pi, F}$ & - & - & - & - & - & - & - & - & - & - & 3.419 \\
\hline \multicolumn{7}{l}{ Loss under commitment in inflation targeting regime: } \\
\hline \hline
\end{tabular}

Table 3: Welfare Loss under the Partial Exchange Rate Targeting, \% of steady state consumption.

Note that if $\omega_{e}=0$ then the fast equilibrium does not exist: we are in the regime of pure inflation targeting, with two different equilibria, but the 'wet/impatient' equilibrium cannot be obtained from the fast equilibrium under the partial exchange rate targeting by tending $\omega_{e}$ to zero. We report the loss $W^{\Pi, F}$ in the fifth line for comparison - this is the loss in the wet/impatient equilibrium under the pure inflation targeting. Note that the welfare losses for the fast equilibrium are higher in the partial exchange rate targeting regime than in the pure inflation targeting regime.

In contrast to policy under commitment, adding additional targets to the social objective of a discretionary policymaker can improve the overall policy outcome. There are many known examples of 'optimal delegation', among others Woodford (2003b) on interest rate smoothing, Walsh (2003) on speed-limit policy and Svensson (1999) and Vestin (2006) on price level targeting. Apparently, an additional exchange rate target does not play a similar role. Lines two and three in Table 3 report social welfare for the partial exchange rate targeting scenarios for the two equilibria, slow and fast $\left(S\right.$ and $F$ ). The social loss monotonically rises with $\omega_{e}$ in the best (slow) equilibrium. The social loss in the fast equilibrium can be slightly reduced with an appropriate choice of $\omega_{e}\left(\omega_{e}=0.05\right)$. However the improvement is only marginal. Moreover, the introduction of the exchange rate target into the otherwise social welfare function is the reason for the existence of the worst equilibrium. We therefore conclude that exchange rate targeting does not solve "the problem of optimal delegation' and is not desirable.

Figure 3 plots the impulse responses of an external cost push shock under the three regimes. The dotted line plots the commitment solution under pure inflation targeting (i.e. using the social welfare function). This is the best possible outcome. The solid and the dashed lines demonstrate responses under discretion when the policymaker imposes $\omega_{e}=0.05$. The impulse responses are very similar to those plotted in the third panel of Figure 2, there are only small differences because of the inability to keep the exchange rate exactly on target.

\section{Conclusion}

This paper demonstrates how a mainstream open economy model with incomplete financial markets can have multiple equilibria under discretionary monetary policy. A policymaker with a given objective can choose to stabilize the economy either slowly or quickly. Depending on private sector beliefs how fast the economy will adjust back to its steady state one of these equilibria will prevail.

We demonstrate that the introduction of nominal exchange rate targeting into the policy 
objective of a discretionary policymaker, that is commonly adopted in developing and emerging countries, does not solve the 'optimal delegation' problem - it only leads to higher social losses.

We believe that the presented model is capable of explaining recent empirical evidence on exchange rate behaviour: there can be switches in regime that are characterized by changes in nominal exchange rate volatility. This can happen for a wide and realistic class of policy objectives, as long as the policymaker acts under discretion and there is at least one predetermined state variable in the system. A sufficiently complex model with these features will retain multiplicity of equilibria and should be able to replicate the observed volatilities of key macroeconomic variables, in particular the nominal exchange rate.

\section{A Discretionary Policy in LQ RE Models}

Our linearized model equations comprise a linear rational expectations model; the criterion functions that our central bank will minimise are all quadratic. Our problem is therefore a special case of a general class of linear-quadratic rational expectations regulator problems. In this short section, we describe this general class of problems, and the types of equilibria that arise, formally.

We assume a non-singular linear deterministic rational expectations model of the type described by Blanchard and Kahn (1980), augmented by a vector of control instruments. Specifically, the evolution of the economy is explained by the following system: ${ }^{23}$

$$
\left[\begin{array}{c}
y_{t+1} \\
\mathcal{E}_{t} x_{t+1}
\end{array}\right]=\left[\begin{array}{cc}
A_{11} & A_{12} \\
A_{21} & A_{22}
\end{array}\right]\left[\begin{array}{c}
y_{t} \\
x_{t}
\end{array}\right]+\left[\begin{array}{c}
B_{1} \\
B_{2}
\end{array}\right]\left[u_{t}\right]
$$

where $y_{t}$ is an $n_{1}$-vector of predetermined variables with initial conditions $y_{0}$ given, $x_{t}$ is $n_{2^{-}}$ vector of non-predetermined (or jump) variables, and $u_{t}$ is a $k$-vector of policy instruments of the policymaker. For notational convenience we define the $n$-vector $z_{t}=\left(y_{t}^{\prime}, x_{t}^{\prime}\right)^{\prime}$ where $n=n_{1}+n_{2}$.v $\mathcal{E}_{t}$ denotes the expectations operator, conditional on information available at time $t$.

At time $t$ the policymaker has the following optimization problem :

$$
\min _{u_{t}} \mathcal{E}_{t} W_{t}
$$

with the loss function

$$
W_{t}=\frac{1}{2} \sum_{s=t}^{\infty} \beta^{s-t} g_{s}^{\prime} \mathcal{Q} g_{s}=\frac{1}{2} \sum_{s=t}^{\infty} \beta^{s-t}\left(z_{s}^{\prime} Q z_{s}+2 z_{s}^{\prime} P u_{s}+u_{s}^{\prime} R u_{s}\right)
$$

subject to system (25). In addition, any solution to this optimization problem should satisfy the time-consistency constraint: for any $s>t$ the policymaker will choose

$$
u_{s}=\mathcal{E}_{t} u_{s}
$$

The elements of the vector $g_{s}$ are the goal variables of the policymaker, $g_{s}=\mathcal{C}\left(z_{s}^{\prime}, u_{s}^{\prime}\right)^{\prime}$. Matrix $\mathcal{Q}$ is assumed to be symmetric and positive semi-definite. In our formulation the quadratic loss

\footnotetext{
${ }^{23}$ We can work with the deterministic component only. This is without loss of generality because of certainty equivalence (see e.g. Anderson et al. (1996)).
} 
function includes instrument costs, but no assumptions about the invertibility of $R$ need be made. We are looking for solutions that ensure that the loss is finite, i.e. $W_{t}<\infty$.

The sequence of actions within a period is as follows. In the first stage of every period $t$ the policymaker chooses the instrument $u_{t}$, knowing the state $y_{t}$ and taking the process by which private agents behave as given. In the second stage the private sector adjusts its choice variable $x_{t}$. The optimal $x_{t}, u_{t}$ and given $y_{t}$ result in the new level of $y_{t+1}$ by the beginning of the next period $t+1$.

It can be proved the solution in any time $t$ gives a value function which is quadratic in the state variables,

$$
W_{t}=\frac{1}{2} y_{t}^{\prime} S y_{t},
$$

and a pair of linear rules

$$
\begin{aligned}
& u_{t}=-F y_{t}, \\
& x_{t}=-J y_{t}-K u_{t}=-(J-K F) y_{t}=-N y_{t},
\end{aligned}
$$

where $K=-\partial x_{t} / \partial u_{t}$ : in a leadership equilibrium the follower treats the leader's policy instrument parametrically. Matrix $F$ describes the policy reaction of the policymaker. Matrix $N$ defines the reduced form reaction function of the private sector.

If we find $F$ and $N$ then the evolution of the dynamic system under control can be written as:

$$
y_{t+1}=\left(A_{11}-A_{12} N-B_{1} F\right) y_{t}=\mathcal{M} y_{t},
$$

and the economy will be stable if all eigenvalues of transition matrix $\mathcal{M}$ are inside the unit circle.

Definition 1 The system of first order conditions to optimization problem (25)-(28) for matrices $\{N, S, F\}$ can be written in the following form:

$$
\begin{aligned}
S & =Q^{*}+\beta A^{* \prime} S A^{*}-\left(P^{* \prime}+\beta B^{* \prime} S A^{*}\right)^{\prime} F, \\
F & =\left(R^{*}+\beta^{\prime} B^{*} S B^{*}\right)^{-1}\left(P^{* \prime}+\beta B^{* \prime} S A^{*}\right), \\
N & =\left(A_{22}+N A_{12}\right)^{-1}\left(\left(A_{21}-B_{2} F\right)+N\left(A_{11}-B_{1} F\right)\right), \\
Q^{*} & =Q_{11}-Q_{12} J-J^{\prime} Q_{21}+J^{\prime} Q_{22} J, P^{*}=J^{\prime} Q_{22} K-Q_{12} K+P_{1}-J^{\prime} P_{2}, \\
R^{*} & =K^{\prime} Q_{22} K+R-K^{\prime} P_{2}-P_{2}^{\prime} K, A^{*}=A_{11}-A_{12} J, B^{*}=B_{1}-A_{12} K, \\
J & =\left(A_{22}+N A_{12}\right)^{-1}\left(A_{21}+N A_{11}\right), K=\left(A_{22}+N A_{12}\right)^{-1}\left(B_{2}+N B_{1}\right) .
\end{aligned}
$$

The proof can be found in e.g. Blake and Kirsanova (2008). There is a one-to-one mapping between equilibrium trajectories and $\left\{y_{s}, x_{s}, u_{s}\right\}_{s=t}^{\infty}$ and the triplet $\mathcal{T}=\{N, S, F\}$, so it is convenient to continue with definition of policy equilibrium in terms of $\mathcal{T}$, not trajectories. Hence, in what follows it is convenient to use the following definition.

Definition 2 A triplet $\mathcal{T}=\{N, S, F\}$ is a discretionary equilibrium if it satisfies the system of FOCs (32)-(37). 
It is apparent from system (32)-(37) that matrices $N, S$ and $F$ satisfy three quadratic algebraic matrix equations (Riccati equations) (32)-(34), where the coefficients in these equations are also non-linear functions of model matrices and matrix $N$. This makes the whole system (32)-(37) very non-linear and it is not surprising that it may have many solution triplets $\mathcal{T}^{J}=\left\{N^{J}, S^{J}, F^{J}\right\}$, $J=1, . . M$ where $M$ is the total number of solutions. Blake and Kirsanova (2008) investigate properties of these discretionary solutions and Dennis and Kirsanova (2009) discuss equilibrium selection mechanisms. In the following we shall only consider equilibria that are Iterative Expectations stable under joint learnig (see also Evans and Honkapohja (2001)).

\section{B Discretionary Equilibria in Inflation Targeting Regime}

Following Appendix A we demonstrate how we find the discretionary equilibria under the regime of inflation targeting.

\section{B.1 The system in the matrix form}

For the inflation targeting regime it is convenient to rewrite the dynamic system in the gap form using the notation $z_{t}=\hat{Z}_{t}-\hat{Z}_{t}^{n}$ for any variable $Z_{t}$. We can substitute out all static variables in order to come to the following reduced form optimization problem, written in a matrix form. We only work with the deterministic part as the model is certainty equivalent and the stochastic part can be added later in a unique way (Anderson et al. (1996)).

The objective function can be written as:

$$
\frac{1}{2} \sum_{s=t}^{\infty} \beta^{s-t}\left(\left[\begin{array}{c}
s_{t} \\
\pi_{H t} \\
c_{t}
\end{array}\right]^{\prime}\left[\begin{array}{ccc}
\alpha^{2} \eta^{2} \omega(2-\alpha)^{2}(1-\gamma)^{2} & 0 & \alpha \eta \omega(1-\alpha)(1-\gamma)^{2} \\
0 & 1 & 0 \\
\alpha \eta \omega(1-\alpha)(2-\alpha)(1-\gamma)^{2} & 0 & \omega(1-\alpha)^{2}(1-\gamma)^{2}
\end{array}\right]\left[\begin{array}{c}
s_{t} \\
\pi_{H t} \\
c_{t}
\end{array}\right]\right) .
$$

We optimize the objective function subject to the dynamic system:

$$
\begin{aligned}
& {\left[\begin{array}{c}
d_{t} \\
s_{t+1} \\
\pi_{H t+1} \\
c_{t+1}
\end{array}\right]=\left[\begin{array}{ccc}
\frac{1}{\beta} & \frac{\alpha}{\beta}(1-\gamma)(\eta(2-\alpha)-1) \\
\frac{\delta}{\beta} & \frac{\alpha \lambda(\phi \eta(2-\alpha)(1-\gamma)+1)}{\beta}+\frac{\alpha \delta(1-\gamma)(\eta(2-\alpha)-1)}{\beta}+1 & \\
0 & -\frac{\alpha \lambda(\phi \eta(2-\alpha)(1-\gamma)+1)}{\beta} & \\
-\frac{\alpha \delta}{\sigma \beta} & \frac{\alpha \lambda(1-\alpha)(\phi \eta(2-\alpha)(1-\gamma)+1)}{\sigma \beta}-\frac{\alpha^{2} \delta(1-\gamma)(\eta(2-\alpha)-1)}{\sigma \beta} &
\end{array}\right]} \\
& \left.\begin{array}{ccc} 
& 0 & -\frac{\alpha}{\beta}(1-\gamma) \\
\ldots & -\frac{1}{\beta} & \frac{\lambda(\sigma+\phi(1-\alpha)(1-\gamma))}{\beta}-\frac{\alpha \delta(1-\gamma)}{\beta} \\
& \frac{1}{\beta} & -\frac{\lambda(\sigma+\phi(1-\alpha)(1-\gamma))}{\beta} \\
-\frac{(1-\alpha)}{\sigma \beta} & \frac{\alpha^{2} \delta(1-\gamma)}{\sigma \beta}+\frac{\lambda(1-\alpha)(\sigma+\phi(1-\alpha)(1-\gamma))}{\sigma \beta}+1
\end{array}\right]\left[\begin{array}{c}
d_{t-1} \\
s_{t} \\
\pi_{H t} \\
c_{t}
\end{array}\right]+\left[\begin{array}{c}
0 \\
1 \\
0 \\
\frac{(1-\alpha)}{\sigma}
\end{array}\right]\left[i_{t}\right],
\end{aligned}
$$

Variables $c_{t}, \pi_{H t}$ and $s$ are non-predetermined, while $d_{t-1}$ is a predetermined variable and $i_{t}$ is 
the instrument of the policymaker. The system matrices needed for computation are:

$$
\begin{aligned}
& A_{11}=\left[\frac{1}{\beta}\right], A_{12}=\left[\frac{\alpha}{\beta}(1-\gamma)(\eta(2-\alpha)-1) \quad 0 \quad-\frac{\alpha}{\beta}(1-\gamma)\right], B_{1}=[0], \\
& A_{21}=\left[\begin{array}{c}
\frac{\delta}{\beta} \\
0 \\
-\frac{\alpha \delta}{\sigma \beta}
\end{array}\right], B_{2}=\left[\begin{array}{c}
1 \\
0 \\
\frac{(1-\alpha)}{\sigma}
\end{array}\right] \\
& A_{22}=\left[\begin{array}{ccc}
\frac{\alpha \lambda(\phi \eta(2-\alpha)(1-\gamma)+1)+\alpha \delta(1-\gamma)(\eta(2-\alpha)-1)+\beta}{\beta} & -\frac{1}{\beta} & \frac{\lambda(\sigma+\phi(1-\alpha)(1-\gamma))-\alpha \delta(1-\gamma)}{\beta} \\
-\frac{\alpha \lambda(\phi \eta(2-\alpha)(1-\gamma)+1)}{\beta} & \frac{1}{\beta} & -\frac{\lambda(\sigma+\phi(1-\alpha)(1-\gamma))}{\beta} \\
\frac{\alpha \lambda(1-\alpha)(\phi \eta(2-\alpha)(1-\gamma)+1)-\alpha^{2} \delta(1-\gamma)(\eta(2-\alpha)-1)}{\sigma \beta} & -\frac{(1-\alpha)}{\sigma \beta} & \frac{\alpha^{2} \delta(1-\gamma)+\lambda(1-\alpha)(\sigma+\phi(1-\alpha)(1-\gamma))+\sigma \beta}{\sigma \beta}
\end{array}\right], \\
& Q_{11}=[0], Q_{12}=\left[\begin{array}{lll}
0 & 0 & 0
\end{array}\right] \text {, } \\
& Q_{21}=Q_{12}^{\prime} \text {, and } R=[0], P_{1}=[0] \text {, } \\
& Q_{22}=\left[\begin{array}{ccc}
\alpha^{2} \eta^{2} \omega(2-\alpha)^{2}(1-\gamma)^{2} & 0 & \alpha \eta \omega(1-\alpha)(2-\alpha)(1-\gamma)^{2} \\
0 & 1 & 0 \\
\alpha \eta \omega(1-\alpha)(2-\alpha)(1-\gamma)^{2} & 0 & \omega(1-\alpha)^{2}(1-\gamma)^{2}
\end{array}\right], P_{2}=\left[\begin{array}{l}
0 \\
0 \\
0
\end{array}\right] .
\end{aligned}
$$

\section{B.2 The policymaker's reaction function and the value function}

Suppose the reaction of the private sector can be written in the following linear form with indeterminate coefficients of matrices $J$ and $K$ :

$$
\left[\begin{array}{c}
s_{t} \\
\pi_{H t} \\
c_{t}
\end{array}\right]=-\left[\begin{array}{c}
J_{s} \\
J_{\pi} \\
J_{c}
\end{array}\right]\left[d_{t-1}\right]-\left[\begin{array}{c}
K_{s} \\
K_{\pi} \\
K_{c}
\end{array}\right]\left[i_{t}\right],
$$

and compute the following scalars (see equations (35)-(37)):

$$
\begin{aligned}
Q^{*} & =\omega(1-\delta)^{2} \theta^{2}-2 \omega(1-\delta) \theta^{2} J_{k}-2 \zeta \omega(1-\delta) \theta J_{c} \\
& +J_{\pi}^{2}+\zeta^{2} \omega J_{c}^{2}+2 \zeta \theta \omega J_{c} J_{k}+\omega \theta^{2} J_{k}^{2}, \\
P^{*} & =\omega \theta^{2} K_{k} J_{k}+\omega \zeta \theta K_{c} J_{k}+J_{\pi} K_{\pi}+\zeta \omega \theta K_{k} J_{c}+\zeta^{2} \omega K_{c} J_{c} \\
& -\omega(1-\delta) \theta^{2} K_{k}-\omega \zeta(1-\delta) \theta K_{c}, \\
R^{*} & =\theta^{2} \omega K_{k}^{2}+K_{\pi}^{2}+\zeta^{2} \omega K_{c}^{2}+2 \zeta \omega \theta K_{c} K_{k}, \\
A^{*} & =-J_{k}, \\
B^{*} & =-K_{k} .
\end{aligned}
$$

Then, substitute steady state version of equation (33) into equation (32) and obtain a quadratic equation for the scalar variable $S$ that can be written as:

$$
\beta B^{* 2} S^{2}+\left(R^{*}-\beta\left(Q^{*} B^{* 2}-2 P^{*} B^{*} A^{*}+R^{*} A^{* 2}\right)\right) S+\left(P^{* 2}-Q^{*} R^{*}\right)=0 .
$$


It is easy to show that the product of the two eigenvalues of the quadratic equation is negative:

$$
\begin{aligned}
& P^{* 2}-Q^{*} R^{*}=-\frac{\omega}{\delta^{2}}\left(\zeta K_{\pi}-K_{\pi}+\delta K_{\pi}-\zeta \delta K_{\pi}-J_{\pi} K_{k}+K_{\pi} J_{k}\right. \\
& \left.+\zeta J_{\pi} K_{k}-\zeta K_{\pi} J_{k}-\zeta \delta J_{\pi} K_{c}+\zeta \delta K_{\pi} J_{c}\right)^{2}<0 .
\end{aligned}
$$

It also immediately follows that the determinant of this equation is positive:

$$
D=\left(R^{*}-\beta\left(Q^{*} B^{* 2}-2 P^{*} B^{*} A^{*}+R^{*} A^{* 2}\right)\right)^{2}-4 \beta B^{* 2}\left(P^{* 2}-Q^{*} R^{*}\right)>0,
$$

as the second term is negative.

Therefore, the two eigenvalues of (38) are always real and of different signs. Since we are looking for a positive value function $S$, the solution is unique. We can easily find it with conventional methods for solving quadratic equations. Having found $S$ we can uniquely determine the optimal discretionary policy as the reaction function:

$$
F=\frac{P^{*}+\beta B^{*} A^{*} S}{R^{*}+\beta B^{* 2} S} .
$$

Note that in equations (38) and (39) all coefficients depend on $J_{k}, J_{\pi}, J_{c}, K_{k}, K_{\pi}$, and $K_{c}$. Equations (37) suggest that all $J$ and $K$ are, in their turn, functions of $N_{k}, N_{\pi}$ and $N_{c}$. Therefore $F=F\left(S\left(N_{k}, N_{\pi}, N_{c}\right)\right)=F\left(N_{k}, N_{\pi}, N_{c}\right)$ depends on the three coefficients of the reaction function of the private sector.

\section{B.3 The private sector's reaction function}

This section completes the analytical characterization of the solution to the problem. Here we derive the private sector's reaction function and construct private sector equilibria.

The pair of linear rules (29)-(30) yields the following reaction function for the policymaker:

$$
i_{t}=-F d_{t-1}
$$

and for the private sector the reaction function is:

$$
\left[\begin{array}{c}
s_{t} \\
\pi_{t} \\
c_{t}
\end{array}\right]=-\left[\begin{array}{c}
N_{s} \\
N_{\pi} \\
N_{c}
\end{array}\right]\left[d_{t-1}\right] .
$$

The private sector's reaction function solves (34), that is a system of three quadratic equations 
for $N_{s}, N_{\pi}$ and $N_{c}$ :

$$
\begin{aligned}
0= & \frac{1}{\beta} N_{s}+\frac{\delta}{\beta}-F-\left(\frac{\alpha}{\beta} N_{s}^{2}(1-\gamma)(\eta(2-\alpha)-1)-\frac{\alpha}{\beta} N_{c} N_{s}(1-\gamma)\right) \\
& -\left(N_{c}\left(-\frac{\alpha}{\beta} \delta(1-\gamma)+\frac{\lambda}{\beta}(\sigma+\phi(1-\alpha)(1-\gamma))\right)-\frac{1}{\beta} N_{\pi}\right) \\
& -N_{s}\left(\frac{\alpha \delta(1-\gamma)(\eta(2-\alpha)-1)}{\beta}+\frac{\alpha \lambda(\phi \eta(2-\alpha)(1-\gamma)+1)}{\beta}+1\right), \\
0= & \frac{1}{\beta} N_{\pi}-\left(-\frac{\alpha}{\beta} N_{\pi} N_{c}(1-\gamma)+\frac{\alpha}{\beta} N_{\pi} N_{s}(1-\gamma)(\eta(2-\alpha)-1)\right) \\
& -\left(\frac{1}{\beta} N_{\pi}-\frac{\lambda(\sigma+\phi(1-\alpha)(-\gamma+1))}{\beta} N_{c}-\frac{\alpha \lambda(\phi \eta(2-\alpha)(1-\gamma)+1)}{\beta} N_{s}\right), \\
0 & \frac{1}{\beta} N_{c}-\frac{\alpha \delta}{\sigma \beta}-\frac{(1-\alpha)}{\sigma} F-\left(\frac{\alpha}{\beta} N_{c} N_{s}(1-\gamma)(\eta(2-\alpha)-1)-\frac{\alpha}{\beta} N_{c}^{2}(1-\gamma)\right) \\
& -N_{s}\left(\frac{\alpha \lambda(1-\alpha)(\phi \eta(2-\alpha)(1-\gamma)+1)}{\sigma \beta}-\frac{\alpha^{2} \delta(1-\gamma)(\eta(2-\alpha)-1)}{\sigma \beta}\right) \\
& +\frac{(1-\alpha)}{\sigma \beta} N_{\pi}-N_{c}\left(\frac{\alpha^{2} \delta(1-\gamma)}{\sigma \beta}+\frac{\lambda(1-\alpha)(\sigma+\phi(1-\alpha)(1-\gamma))}{\sigma \beta}+1\right) .
\end{aligned}
$$

Note that the second equation is linear in $N_{\pi}$, does not contain $F$, and can be easily solved as $N_{\pi}=N_{\pi}\left(N_{s}, N_{c}\right)$. We can substitute out $N_{\pi}$ from the first and the third equation and come to a two-equation polynomial system (40) and (42), that can be easily solved numerically. We plot solutions to each equation in the top panel of Figure 4. When these lines intersect we have a solution to the system (40) and (42). They intersect at five points, denoted by circles and diamonds. Having found all solutions for $\left\{N_{s}(F), N_{c}(F)\right\}$ we can also compute $N_{\pi}=N_{\pi}\left(N_{s}(F), N_{c}(F)\right)=N_{\pi}(F)$ for each of them.

Given $F$ we can substitute $N$ into the dynamic system (31) and check that only two solutions, denoted by circles in the top panel of Figure 4, ensure stability of the system; so all eigenvalues of the matrix $M$ are inside the unit circle. The other three solutions are unstable. Although the stability properties can change if we vary $F$, we have checked that this is not the case. We will ignore unstable solutions in what follows.

To summarize, for a given $F$ we can find a solution triplet $\left\{N_{s}(F), N_{\pi}(F), N_{c}(F)\right\}$, which describes the equilibrium response of the private sector to a policy action. We have found five private sector equilibria, as shown in Figure 4, top panel, but only two of them have economic sense.

\section{B.4 Discretionary solutions}

A discretionary solution, by definition, is a triplet of matrices $\{N, S, F\}$ which is an asymptotically stable steady state of system (32)-(34). In other words, all solutions can be described as pints of intersection of solutions of the system (32)-(33) with solutions of equation (34), as we demonstrate next.

The top panel of Figure 4 plots solution pairs $\left\{N_{c}(F), N_{s}(F)\right\}$ for a given value of $F$. If we vary $F$ then each of the five points becomes a one-dimensional curve in the three-dimensional 


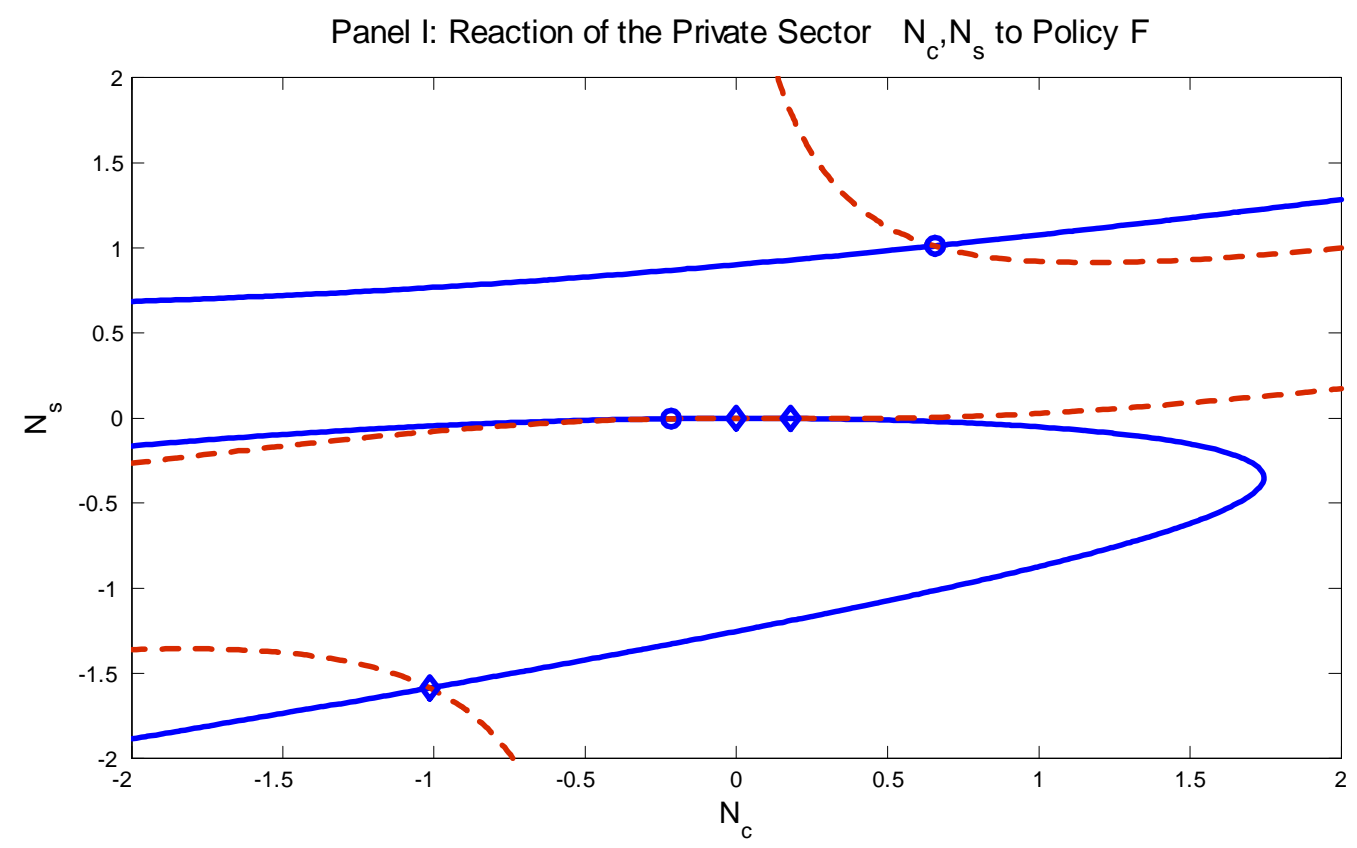

Discretionary Equilibria

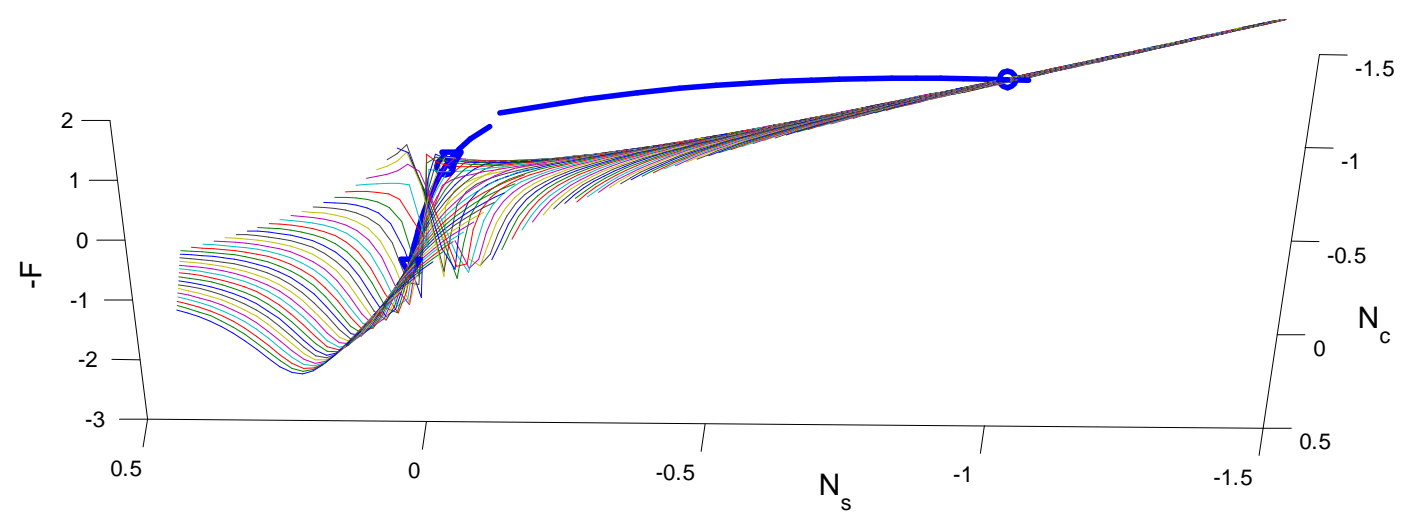

Figure 4: Discretionary Solution 
space with coordinates $N_{c}, N_{s}$ and $F$. Similarly, equations (38) and (39) define $F$ for every triplet $\left\{N_{s}, N_{\pi}, N_{c}\right\}$ and, as $N_{\pi}=N_{\pi}\left(N_{s}, N_{c}\right)$, then $F=F\left(N_{s}, N_{c}\right)$. This determines a two-dimensional surface in the same three-dimensional space. Where these curves intersect the surface we have discretionary solutions. We plot the surface and the two curves, that correspond to stable private sector equilibria as described above, in the bottom panel of Figure 4. They intersect in four points so there are four discretionary equilibria. We disregard two of them as they cannot be located neither by backward induction as discussed in Blake and Kirsanova (2008) nor are they Iterative Expectations-stable under joint learning as discussed in Dennis and Kirsanova (2009). We discuss the economic properties of the remaining equilibria in the paper.

\section{Details of Derivations}

\section{C.1 Large closed economy (Rest of the World)}

We assume that $\hat{\imath}_{t}^{*}$ is chosen optimally under commitment. This will guarantee price level stability in the foreign country and give a convenient benchmark.

The problem is standard. Woodford (2003a) demonstrates that the policymaker will chose interest rate gap $i_{t}^{*}=\hat{\imath}_{t}^{*}-\hat{\imath}_{t}^{* n}$ in order to minimise social loss

$$
\sum_{t=0}^{\infty} \beta^{t}\left(\left(\pi_{t}^{*}\right)^{2}+\frac{\lambda}{\varepsilon}\left(c_{t}^{*}\right)^{2}\right)
$$

where $\pi_{t}^{*}=\hat{\pi}_{t}^{*}-\hat{\pi}_{t}^{* n}$ is inflation gap and $c_{t}^{*}=\hat{C}_{t}^{*}-\hat{C}_{t}^{* n}$ is consumption (output) gap, and

$$
\hat{\pi}_{t}^{* n}=0, \hat{C}_{t}^{* n}=\frac{(\phi+1)}{(\sigma+\phi)} \hat{A}_{t}^{*}, \hat{\imath}_{t}^{* n}=-\frac{\sigma\left(1-\rho_{a^{*}}\right)(\phi+1)}{(\sigma+\phi)} \hat{A}_{t}^{*} .
$$

The evolution of the economy under control can be written as:

$$
\begin{aligned}
\eta_{t+1}^{*} & =\rho_{\eta^{*}} \eta_{t}^{*}, \\
\zeta_{1 t} & =z_{10} \eta_{t}^{*}+z_{11} \zeta_{1 t-1}+z_{12} \zeta_{2 t-1}, \\
\zeta_{2 t} & =z_{20} \eta_{t}^{*}+z_{21} \zeta_{1 t-1}-1+z_{22} \zeta_{2 t-1}, \\
\pi_{t}^{*} & =n_{\pi 0} \eta_{t}^{*}+n_{\pi 1} \zeta_{1 t-1}+n_{\pi 2} \zeta_{2 t-1}, \\
c_{t}^{*} & =n_{c 0} \eta_{t}^{*}+n_{c 1} \zeta_{1 t-1}+n_{c 2} \zeta_{2 t-1}, \\
i_{t}^{*} & =f_{0} \eta_{t}^{*}+f_{1} \zeta_{1 t-1}+f_{2} \zeta_{2 t-1} .
\end{aligned}
$$

And the actual variables evolve as

$$
\begin{aligned}
\eta_{t+1}^{*} & =\rho_{\eta^{*}} \eta_{t}^{*}, \\
\zeta_{1 t} & =z_{10} \eta_{t}^{*}+z_{11} \zeta_{1 t-1}+z_{12} \zeta_{2 t-1}, \\
\zeta_{2 t} & =z_{20} \eta_{t}^{*}+z_{21} \zeta_{1 t-1}+z_{22} \zeta_{2 t-1}, \\
\hat{\pi}_{t}^{*} & =n_{\pi 0} \eta_{t}^{*}+n_{\pi 1} \zeta_{1 t-1}+n_{\pi 2} \zeta_{2 t-1}, \\
\hat{C}_{t}^{*} & =n_{c 0} \eta_{t}^{*}+n_{c 1} \zeta_{1 t-1}+n_{c 2} \zeta_{2 t-1}+\frac{(\phi+1)}{(\sigma+\phi)} \hat{A}_{t}^{*}, \\
\hat{\imath}_{t}^{*} & =f_{0} \eta_{t}^{*}+f_{1} \zeta_{1 t-1}+f_{2} \zeta_{2 t-1}-\frac{\sigma\left(1-\rho_{a^{*}}\right)(\phi+1)}{(\sigma+\phi)} \hat{A}_{t}^{*} .
\end{aligned}
$$




\section{C.2 Small Open Economy: Natural Rates}

The dynamic system for the flexible price equilibrium can be written as

$$
\begin{aligned}
\beta \hat{d}_{t}^{n}= & \hat{d}_{t-1}^{n}-\alpha(1-\gamma) \hat{C}_{t}^{n}-\alpha(1-\gamma)(1-\eta(2-\alpha)) \hat{S}_{t}^{n}+\alpha(1-\gamma) \hat{C}_{t}^{* n}, \\
\hat{\imath}_{t}^{n}= & \hat{\imath}_{t}^{* n}+\hat{S}_{t+1}^{n}-\hat{S}_{t}^{n}-\delta d_{t}^{n}, \\
\hat{C}_{t}^{n}= & \hat{C}_{t+1}^{n}-\frac{1}{\sigma}\left(\hat{\imath}_{t}^{n}-\alpha\left(\hat{S}_{t+1}^{n}-\hat{S}_{t}^{n}\right)\right), \\
0= & (\sigma+\phi(1-\alpha)(1-\gamma)) \hat{C}_{t}^{n}+\alpha(1+\phi \eta(2-\alpha)(1-\gamma)) \hat{S}_{t}^{n} \\
& +\phi \alpha(1-\gamma) \hat{C}_{t}^{* n}+\phi \gamma \hat{G}_{t}-(\phi+1) \hat{A}_{t} .
\end{aligned}
$$

We substitute foreign natural rates and, after some manipulations, obtain:

$$
\begin{aligned}
\beta \hat{d}_{t}^{n} & =\hat{d}_{t-1}^{n}+\xi_{d} \hat{S}_{t}^{n}+u_{t}, \\
\xi_{s} \hat{S}_{t+1}^{n} & =\frac{\delta}{\sigma} d_{t}^{n}+\xi_{s} \hat{S}_{t}^{n}+v_{t},
\end{aligned}
$$

where parameters are

$$
\begin{aligned}
& \xi_{d}=\alpha(1-\gamma)\left(\frac{\alpha(1+\phi \eta(2-\alpha)(1-\gamma))}{(\sigma+\phi(1-\alpha)(1-\gamma))}-(1-\eta(2-\alpha))\right), \\
& \xi_{s}=\left(\frac{\alpha(1+\phi \eta(2-\alpha)(1-\gamma))}{(\sigma+\phi(1-\alpha)(1-\gamma))}+\frac{(1-\alpha)}{\sigma}\right),
\end{aligned}
$$

and shocks $u_{t}$ and $v_{t}$ are composite shocks:

$$
\begin{aligned}
u_{t} & =\frac{\alpha(1-\gamma)\left(\phi \gamma \hat{G}_{t}-(\phi+1) \hat{A}_{t}+\frac{(\sigma+(1-\gamma) \phi)(\phi+1)}{(\sigma+\phi)} \hat{A}_{t}^{*}\right)}{(\sigma+\phi(1-\alpha)(1-\gamma))}, \\
v_{t} & =\frac{\left(\phi \gamma\left(1-\rho_{g}\right) \hat{G}_{t}-\left(1-\rho_{a}\right)(\phi+1) \hat{A}_{t}+\frac{\left(1-\rho_{a^{*}}\right)(\phi+1)(\sigma+(1-\gamma) \phi)}{(\sigma+\phi)} \hat{A}_{t}^{*}\right)}{(\sigma+\phi(1-\alpha)(1-\gamma))} .
\end{aligned}
$$

A solution to system (43)-(44) can be written as:

$$
\begin{aligned}
& \hat{d}_{t}^{n}=\rho_{d} \hat{d}_{t-1}^{n}+\xi_{u} u_{t}+\xi_{v} v_{t}, \\
& \hat{S}_{t}^{n}=s_{d} \hat{d}_{t-1}^{n}+\kappa_{u} u_{t}+\kappa_{v} v_{t},
\end{aligned}
$$

and $\hat{\imath}_{t}^{n}$ and $\hat{C}_{t}^{n}$ can be easily restored. 


\section{C.3 Small Open Economy: Log-Linearised System}

Log-linearised system:

$$
\begin{aligned}
\beta \hat{d}_{t}= & \hat{d}_{t-1}-\alpha(1-\gamma) \hat{C}_{t}+\alpha(1-\gamma)(\eta(2-\alpha)-1) \hat{S}_{t}+\alpha(1-\gamma) \hat{C}_{t}^{*} \\
\hat{\imath}_{t}= & \hat{\imath}_{t}^{*}+\hat{S}_{t+1}-\hat{S}_{t}+\pi_{H, t+1}-\pi_{t+1}^{*}-\delta d_{t} \\
\hat{C}_{t}= & \hat{C}_{t+1}-\frac{1}{\sigma}\left(\hat{\imath}_{t}-\hat{\pi}_{H, t+1}-\alpha\left(\hat{S}_{t+1}-\hat{S}_{t}\right)\right) \\
\hat{\pi}_{H t}= & \beta \mathcal{E}_{t} \hat{\pi}_{H t+1}+\lambda\left((\sigma+\phi(1-\alpha)(1-\gamma)) \hat{C}_{t}+\alpha(1+\phi \eta(2-\alpha)(1-\gamma)) \hat{S}_{t}\right) \\
& +\lambda \phi \alpha(1-\gamma) \hat{C}_{t}^{*}+\lambda \phi \gamma \hat{G}_{t}-\lambda(\phi+1) \hat{A}_{t}+\eta_{t} \\
\hat{C}_{t}^{*}= & \hat{C}_{t+1}^{*}-\frac{1}{\sigma}\left(\hat{\imath}_{t}^{*}-\hat{\pi}_{t+1}^{*}\right) \\
\hat{\pi}_{t}^{*}= & \beta \hat{\pi}_{t+1}^{*}+\lambda\left((\sigma+\phi) \hat{C}_{t}^{*}-(\phi+1) \hat{A}_{t}^{*}\right)+\eta_{t}^{*}
\end{aligned}
$$

Substitute the expression for $\hat{\imath}_{t}^{*}$. We obtain the following system:

$$
\begin{aligned}
\zeta_{1 t}= & z_{10} \eta_{t}^{*}+z_{11} \zeta_{1 t-1}+z_{12} \zeta_{2 t-1} \\
\zeta_{2 t}= & z_{20} \eta_{t}^{*}+z_{21} \zeta_{1 t-1}+z_{22} \zeta_{2 t-1} \\
\beta \hat{d}_{t}= & \hat{d}_{t-1}-\alpha(1-\gamma) \hat{C}_{t}+\alpha(1-\gamma)(\eta(2-\alpha)-1) \hat{S}_{t}+\alpha(1-\gamma) \hat{C}_{t}^{*} \\
\hat{\imath}_{t}= & \hat{S}_{t+1}-\hat{S}_{t}+\pi_{H, t+1}-\delta d_{t}-\frac{\sigma\left(1-\rho_{a^{*}}\right)(\phi+1)}{(\sigma+\phi)} \hat{A}_{t}^{*}+\left(f_{c 0}-n_{\pi 0} \rho_{\eta^{*}}-n_{\pi 1} z_{10}-n_{\pi 2} z_{20}\right) \eta_{t}^{*} \\
& +\left(f_{c 1}-n_{\pi 1} z_{11}-n_{\pi 2} z_{21}\right) \zeta_{1 t-1}+\left(f_{c 2}-n_{\pi 1} z_{12}-n_{\pi 2} z_{22}\right) \zeta_{2 t-1} \\
\hat{C}_{t}= & \hat{C}_{t+1}-\frac{1}{\sigma}\left(\hat{\imath}_{t}-\hat{\pi}_{H, t+1}-\alpha\left(\hat{S}_{t+1}-\hat{S}_{t}\right)\right) \\
\hat{\pi}_{H t}= & \beta \mathcal{E}_{t} \hat{\pi}_{H t+1}+\lambda\left((\sigma+\phi(1-\alpha)(1-\gamma)) \hat{C}_{t}+\alpha(1+\phi \eta(2-\alpha)(1-\gamma)) \hat{S}_{t}\right) \\
& +\lambda \phi \alpha(1-\gamma) \hat{C}_{t}^{*}+\lambda \phi \gamma \hat{G}_{t}-\lambda(\phi+1) \hat{A}_{t}+\eta_{t} \\
\hat{C}_{t}^{*}= & \hat{C}_{t+1}^{*}-\frac{1}{\sigma}\left(\hat{\imath}_{t}^{*}-\hat{\pi}_{t+1}^{*}\right) \\
\hat{\pi}_{t}^{*}= & \beta \hat{\pi}_{t+1}^{*}+\lambda\left((\sigma+\phi) \hat{C}_{t}^{*}-(\phi+1) \hat{A}_{t}^{*}\right)+\eta_{t}^{*}
\end{aligned}
$$

We have four independent shocks $\eta_{t}, \eta_{t}^{*}, \hat{A}_{t}, \hat{A}_{t}^{*}$. We assume that they are independent $\operatorname{AR}(1)$ processes.

\section{C.4 Small Open Economy: System in Gaps}

We assume that monetary policy use interest rate gap $i_{t}=\hat{\imath}_{t}-\hat{\imath}_{t}^{n}$ in order to minimise social loss

$$
\sum_{t=0}^{\infty} \beta^{t}\left(\pi_{H t}^{2}+\frac{\lambda}{\varepsilon} y_{t}^{2}\right)
$$


where $\pi_{t}=\hat{\pi}_{H t}-\hat{\pi}_{H t}^{n}$ is inflation gap and $y_{t}=\hat{Y}_{t}-\hat{Y}_{t}^{n}$ is output gap. The system of constraints can be written as follows, and

$$
\hat{\pi}_{t}^{* n}=0, \hat{C}_{t}^{* n}=\frac{(\phi+1)}{(\sigma+\phi)} \hat{A}_{t}^{*}, \hat{\imath}_{t}^{* n}=-\frac{\sigma\left(1-\rho_{a^{*}}\right)(\phi+1)}{(\sigma+\phi)} \hat{A}_{t}^{*}
$$

The evolution of the economy under control can be written as:

$$
\begin{aligned}
\zeta_{1 t}= & z_{10} \eta_{t}^{*}+z_{11} \zeta_{1 t-1}+z_{12} \zeta_{2 t-1} \\
\zeta_{2 t}= & z_{20} \eta_{t}^{*}+z_{21} \zeta_{1 t-1}+z_{22} \zeta_{2 t-1} \\
\beta d_{t}= & d_{t-1}-\alpha(1-\gamma) c_{t}+\alpha(1-\gamma)(\eta(2-\alpha)-1) s_{t} \\
& +\alpha(1-\gamma) n_{c 0} \eta_{t}^{*}+\alpha(1-\gamma) n_{c 1} \zeta_{1 t-1}+\alpha(1-\gamma) n_{c 2} \zeta_{2 t-1} \\
i_{t}= & s_{t+1}-s_{t}+\pi_{H, t+1}-\delta d_{t}+\left(f_{c 0}-n_{\pi 0} \rho_{\eta^{*}}-n_{\pi 1} z_{10}-n_{\pi 2} z_{20}\right) \eta_{t}^{*} \\
& +\left(f_{c 1}-n_{\pi 1} z_{11}-n_{\pi 2} z_{21}\right) \zeta_{1 t-1}+\left(f_{c 2}-n_{\pi 1} z_{12}-n_{\pi 2} z_{22}\right) \zeta_{2 t-1} \\
c_{t}= & c_{t+1}-\frac{1}{\sigma}\left(i_{t}-\pi_{H, t+1}-\alpha\left(s_{t+1}-s_{t}\right)\right) \\
\pi_{H t}= & \beta \mathcal{E}_{t} \pi_{H t+1}+\lambda\left((\sigma+\phi(1-\alpha)(1-\gamma)) c_{t}+\alpha(1+\phi \eta(2-\alpha)(1-\gamma)) s_{t}\right) \\
& +\lambda \phi \alpha(1-\gamma) n_{c 0} \eta_{t}^{*}+\lambda \phi \alpha(1-\gamma) n_{c 1} \zeta_{1 t-1}+\lambda \phi \alpha(1-\gamma) n_{c 2} \zeta_{2 t-1}+\eta_{t}
\end{aligned}
$$

and the goal variable

$$
\begin{aligned}
y_{t}= & (1-\alpha)(1-\gamma) c_{t}-\eta \alpha(\alpha-2)(1-\gamma) s_{t}+\alpha(1-\gamma) c_{t}^{*} \\
= & (1-\alpha)(1-\gamma) c_{t}-\eta \alpha(\alpha-2)(1-\gamma) s_{t}+\alpha(1-\gamma) n_{c 0} \eta_{t}^{*} \\
& +\alpha(1-\gamma) n_{c 1} \zeta_{1 t-1}+\alpha(1-\gamma) n_{c 2} \zeta_{2 t-1}
\end{aligned}
$$

\section{References}

Anderson, E. W., L. P. Hansen, E. R. McGrattan, and T. J. Sargent (1996). Mechanics of Forming and Estimating Dynamic Linear Economies. In H.M.Amman, D.A.Kendrick, and J.Rust (Eds.), Handbook of Computational Economics, pp. 171-252. Elsevier.

Arize, A., T. Osang, and D. Slottje (2000). Exchange-rate volatility and foreign trade: evidence from thirteen LDCŠs. Journal of Business and Economic Statistics 18, 10-17.

Barro, R. J. and D. B. Gordon (1983). Rules, Discretion and Reputation in a Model of Monetary Policy. Journal of Monetary Economics 12, 101-121.

Beetsma, R. and H. Jensen (2004). Mark-up Fluctuations and Fiscal Policy Stabilization in a Monetary Union. Journal of Macroeconomics 26, 357-376.

Benigno, P. (2001). Price Stability with Imperfect Financial Integration. CPER Discussion Paper No.2854.

Benigno, P. (2009). Price Stability with Imperfect Financial Integration. Journal of Money, Credit and Banking 41(1), 121-149. 
Bergin, P. (2006). How Well can the New Open Economy Macroeconomics Explain the Exchange Rate and the Current account. Journal of International Money and Finance 25(5), 675-701.

Blake, A. P. and T. Kirsanova (2008). Discretionary Policy and Multiple Equilibria in LQ RE Models. Mimeo, University of Exeter. Available at SSRN: http://ssrn.com/abstract=943032.

Blanchard, O. and C. Kahn (1980). The Solution of Linear Difference Models Under Rational Expectations. Econometrica 48, 1305-1311.

Calvo, G. (1983). Staggered Prices in a Utility-Maximising Framework. Journal of Monetary Economics 12, 383-398.

Calvo, G. and C. Reinhart (2002). Fear of Floating. Quarterly Journal of Economics 117, 379-408.

Chen, S. (2006). Revisiting the interest rate-exchange rate nexus: a Markov-switching approach. Journal of Develpment Economics 79(1), 208-224.

Clarida, R., L. Sarno, M. Taylor, and G. Valente (2003). The out-of-sample success of term structure models as exchange rate predictors: a step beyond. International Economic Review 60, $61-83$.

Clarida, R. H., J. Galí, and M. Gertler (1999). The Science of Monetary Policy: A New Keynesian Perspective. Journal of Economic Literature 3\%, 1661-1707.

Cohen, D. and P. Michel (1988). How Should Control Theory be Used to Calculate a TimeConsistent Government Policy? Review of Economic Studies 55, 263-274.

Cooper, R. and A. John (1988). Coordination Failures in Keynesian Models. Quarterly Journal of Economics 103(3), 441-463.

Corsetti, G. and P. Pesenti (2001). Welfare and Macroeconmic Interdependence. The Quarterly Journal of Economics 116(2), 421-445.

Côte, A. (1994). Exchange Rate Volatility and Trade - A Survey. Working Paper 94-5, Bank of Canada.

Currie, D. and P. Levine (1985). Simple Macropolicy Rules for the Open Economy. The Economic Journal 95, 60-70.

De Paoli, B. (2009a). Monetary Policy and Welfare in a Small Open Economy. Journal of International Economics $77(1), 11-22$.

De Paoli, B. (2009b). Monetary Policy in a Small Open Economy: the Role of the Asset Market Structure. forthcoming in Journal of Money, Credit and Banking.

Dennis, R. and T. Kirsanova (2009). Expectations Traps and Coordination Failures: Selecting Among Multiple Discretionary Equilibria. Mimeo, Federal Reserve Bank of San Francisco. 
Dogolnar, M. (2002). Estimating the impact of exchange rate volatility on exports: evidence from Asian countries. Applied Economics Letters 9, 859-863.

Engel, C. and J. Hamilton (1990). Long Swings in the Dollar: Are They in the Data and Do Markets Know It. American Economics Review 80(4), 689-713.

Engel, C., N. Mark, and K. West (2007). Exchange Rate Models Are Not As Bad As You Think. In NBER Macroeconomics Annual, Volume 22, pp. 381-441.

Evans, G. and S. Honkapohja (2001). Learning and Expectations in Macroeconomics. Princeton University Press.

Galí, J. and T. Monacelli (2005). Monetary Policy and Exchange Rate Volatility in a Small Open Economy. Review of Economic Studies 72, 707-734.

Ghironi, F., J. Lee, and A. Rebucci (2007). The Valuation Channel of External Adjustment. unpublished manuscript, Boston College.

Jeanne, O. and A. Rose (2002). Noise Trading and Exchange Rate Regime. Quarterly Journal of Economics 117(2), 537-569.

King, R. and A. Wolman (2004). Monetary Discretion, Pricing Complementarity, and Dynamic Multiple Equilibria. Quarterly Journal of Economics 199(4), 1513-1553.

Lane, P. and M. Milesi-Ferretti (2002). Long-Term Capital Movements. NBER Macroeconomics Annual 16, MIT Press.

Levy-Yeyati, E. and F. Sturzenegger (2005). Classifiying Exchange Rate Regimes: Deeds vs. Words. European Economic Review 49(6), 1603-1635.

Obstfeld, M. and K. Rogoff (1998). Risk and Exchange Rate. NBER Working Papers No.6694.

Prasad, E., K. Rogoff, S.-J. Wei, and M. Kose (2003). Effects of Financial Globalization on Developing Countries: Some Empirical Evidence. International Monetary Fund Occasional Paper 220.

Rahmatsyah, T., G. Rajaguru, and R. Siregar (2002). Exchange-rate volatility, trade and 'fixing for life' in Thailand. Japan and the World Economy 14, 445-470.

Reinhart, C. and K. Rogoff (2004). The Modern History of Exchange Rate Arrangements: A Reinterpretation. Quarterly Journal of Economics 119(1), 1-48.

Rogoff, K. (1985). The optimal degree of commitment to an intermediate monetary target. The Quarterly Journal of Economics 100(4), 1169-1189.

Schmitt-Grohe, S. and M. Uribe (2003). Closing Small Open Economy models. Journal of International Economics 61, 161-185.

Smets, F. and R. Wouters (2003). An Estimated Dynamic Stochastic General Equilibrium Model of the Euro Area. Journal of the European Economic Association 1. 
Söderlind, P. (1999). Solution and Estimation of RE Macromodels with Optimal Policy. European Economic Review 43, 813-823.

Svensson, L. (1997). Optimal Inflation Targets, "Conservative" Central Banks, and Linear Inflation Contracts. The American Economic Review 87(1), 98-114.

Svensson, L. E. (1999). Price Level targeting versus inflation targeting: a free lunch? Journal of Money, Credit and Banking 431(3), 277-295.

Vestin, D. (2006). Price-level versus inflation targeting. Journal of Monetary Economics 53(7), $1361-1376$.

Walsh, C. (2003). Speed Limit Policies: The Output Gap and Optimal Monetary Policy. American Economic Review 93(1), 265-278.

Woodford, M. (2003a). Interest and Prices: Foundations of a Theory of Monetary Policy. Princeton, NJ.: Princeton University Press.

Woodford, M. (2003b). Optimal Interest-Rate Smoothing. Review of Economic Studies 70(4), $861-886$. 